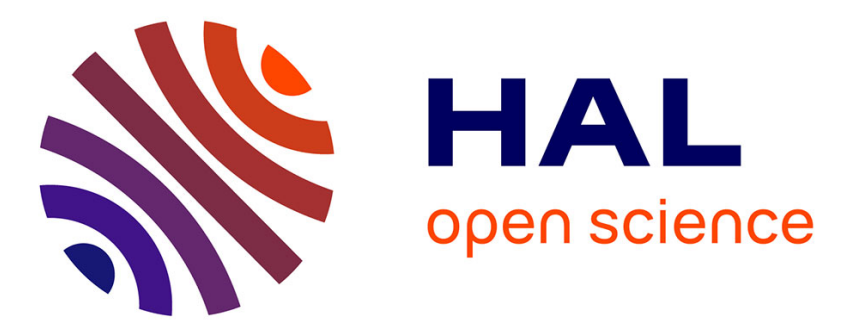

\title{
Probabilistic Completeness Assessment of the Past 30 Years of Seismic Monitoring in northeastern Italy
}

\author{
S. Gentili, M. Sugan, L. Peruzza, D. Schorlemmer
}

\section{To cite this version:}

S. Gentili, M. Sugan, L. Peruzza, D. Schorlemmer. Probabilistic Completeness Assessment of the Past 30 Years of Seismic Monitoring in northeastern Italy. Physics of the Earth and Planetary Interiors, 2011, 10.1016/j.pepi.2011.03.005 . hal-00748751

\section{HAL Id: hal-00748751 \\ https://hal.science/hal-00748751}

Submitted on 6 Nov 2012

HAL is a multi-disciplinary open access archive for the deposit and dissemination of scientific research documents, whether they are published or not. The documents may come from teaching and research institutions in France or abroad, or from public or private research centers.
L'archive ouverte pluridisciplinaire HAL, est destinée au dépôt et à la diffusion de documents scientifiques de niveau recherche, publiés ou non, émanant des établissements d'enseignement et de recherche français ou étrangers, des laboratoires publics ou privés. 


\section{Accepted Manuscript}

Title: Probabilistic Completeness Assessment of the Past 30

Years of Seismic Monitoring in northeastern Italy

Authors: S. Gentili, M. Sugan, L. Peruzza, D. Schorlemmer

PII:

S0031-9201(11)00057-4

DOI: doi:10.1016/j.pepi.2011.03.005

Reference: PEPI 5389

To appear in: Physics of the Earth and Planetary Interiors

Received date: 28-4-2010

Revised date:

Accepted date:

Please cite this article as: Gentili, S., Sugan, M., Peruzza, L., Schorlemmer, D., Probabilistic Completeness Assessment of the Past 30 Years of Seismic Monitoring in northeastern Italy, Physics of the Earth and Planetary Interiors (2010), doi:10.1016/j.pepi.2011.03.005

This is a PDF file of an unedited manuscript that has been accepted for publication. As a service to our customers we are providing this early version of the manuscript. The manuscript will undergo copyediting, typesetting, and review of the resulting proof before it is published in its final form. Please note that during the production process errors may be discovered which could affect the content, and all legal disclaimers that apply to the journal pertain. 


\section{Probabilistic Completeness Assessment of the Past 30 Years of Seismic \\ 2 Monitoring in northeastern Italy}

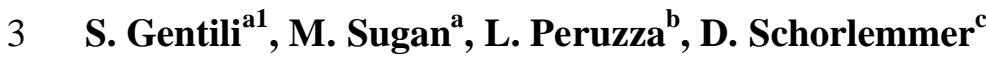

4

5

6

7

8

9

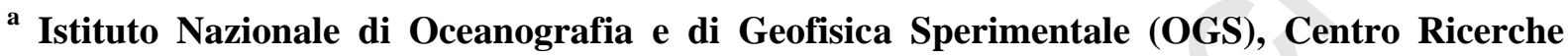
Sismologiche Via Treviso 55, 33100 Cussignacco (Udine), Italy.

b Istituto Nazionale di Oceanografia e di Geofisica Sperimentale (OGS), Centro Ricerche Sismologiche Borgo Grotta Gigante, 42c - 34010 Sgonico (Trieste), ITALY

${ }^{c}$ Southern California Earthquake Center, University of Southern California, Department of Earth Science, 3651 Trousdale Parkway, Los Angeles, CA 90089, United States

\section{Abstract}

We investigate detection probabilities and recording completeness of the seismic network in northeastern Italy, operated by the OGS (Istituto Nazionale di Oceanografia e Geofisica Sperimentale) during the years 1977-2007, using the Probability-based Magnitude of Completeness (PMC) method by Schorlemmer \& Woessner (2008).

Completeness of the dataset is varying in space and time due to the evolution of network geometry, instrumental characteristics, and monitoring and processing strategies over time: this is a common feature for all the regional and national instrumental catalogues that should be properly accounted for in seismicity rates evaluations. For the first time, we quantify with the new PMC method

$1 \quad$ Corresponding author. Tel: +39 040 2140134, Fax: +39 0432522474

E-mail address: $\underline{\text { sgentili@inogs.it }}$ 
detection probabilities of a regional network operating since the late 70's, also including paper records.

PMC is based on empirical data and requires the earthquake catalog containing phase picks, the station locations and on-/off-times, and the attenuation relation used to compute local magnitudes. In the 30-year period, we identified four time windows, roughly corresponding to the main changes in the acquisition system. We reconstructed on-/off-times by merging the available information on instruments with the analysis of inter-pick times at each station.

We revised the relationship between duration and local magnitudes as the calibration of duration magnitude demonstrated to be not homogeneous among the different acquisition systems. Moreover, we introduced some constraints on the application of the PMC method to improve its performance for networks with sparse data and show the role of missing events and of temporary networks on regional completeness maps.

The results demonstrate that the OGS network is detecting earthquakes completely down to magnitude 1.5 for a large part of the Friuli-Venezia-Giulia region since the earliest stages of its functionality; the OGS instrumental catalogue is therefore the most precise and complete dataset available for this area. Our analysis shows that the change from analog to digital systems does not necessarily correspond to an improvement in detection capabilities. The computed time series of completeness maps are available and should be considered for any seismicity study involving data from the OGS network.

Keywords: Probability-based Magnitude of Completeness, Seismometric Networks, Earthquake Databases, North-Eastern Italy, Seismic Attenuation. 
46

\section{Introduction}

The National Institute of Oceanography and Experimental Geophysics (Istituto Nazionale di Oceanografia e Geofisica Sperimentale, OGS) has a long tradition in seismometric monitoring which dates back to pioneer instruments (see Supplementary Online Material). Currently, OGS manages 22 short-period and 11 broad-band stations (see Figure 1).

$<$ Insert Figure 1 here >

To increase the quality of earthquake locations, data from other Italian and international institutions is retrieved, e.g. the Province of Trento (Provincia Autonoma di Trento) and the National Institute of Geophysics and Vulcanology (Istituto Nazionale di Geofisica e Vulcanologia, INGV) in Italy, the Environmental Agency of the Republic of Slovenia (ARSO), and the Austrian Central Institute for Meteorology and Geodynamics (Zentralanstalt für Meteorologie und Geodynamik, ZAMG). From 1977 to 2007 , only short-period stations have been used as triggering stations by the alarm system for real-time seismic monitoring: since 2008, OGS broad-band stations and those managed by other institutions have been gradually added into the automatic alarm system. In 2008, the NEI authoritative region corresponds to the Friuli-Venezia-Giulia (FVG), Veneto (VE), and Provincia Autonoma di Trento (TN) Italian regions (Figure 1), where real-time seismic monitoring and alert warnings are provided; OGS is also providing data of some stations in real time to INGV and foreign institutions.

The earthquake detection threshold of the NEI area (approximately $350 \mathrm{~km}$ wide in longitude, and $300 \mathrm{~km}$ in latitude) is characterized by the network changes, by international borders (to Austria and Slovenia), and by unfavorable site conditions (noisy alluvial plain and off-shore regions). They strongly influence the magnitude of completeness of the OGS earthquake catalog, which counts more than 16,000 located events in period from 6 May 1977 to 31 December 2007.

Several studies were conducted to estimate the completeness of the OGS catalog. Most of them 
were based on analyses of the whole catalog, without investigating spatio-temporal variations of completeness. However, knowledge about these spatio-temporal variations is important for almost any study in statistical seismology or any research involving earthquake catalogs. Wrong completeness estimates may lead to misinterpretation of seismicity rates. Woessner and Wiemer (2005), for example, outlined that if a Gutenberg-Richter (1944) frequency-magnitude distribution with $b$-value equal to 1 is assumed, an error on completeness magnitude of 0.1 leads to a $25 \%$ change in seismic rate, while an error of 0.3 to a factor 2. Since completeness and recording capabilities of a network are strongly heterogeneous over space and time and are easily affected by slight disruptions (e.g. station failure, telemetry failure), a detailed characterization of the network performance is indispensable.

In northeastern Italy, Priolo et al. (2005) estimated a completeness magnitude $\left(M_{\mathrm{c}}\right)$ equal to 2 for the period 1994-2004 on the basis of the Gutenberg-Richter cumulative seismicity rate; similarly, Gentili and Bressan (2007) report completeness in the range of $M_{\mathrm{c}} \sim 2$ in the periods 1980-1990 and 1991-2004. Marcellini and Milani (2003), by analyzing separately three periods (1977-1987, 19881994, and 1995-2002) and three sub-regions inside the area covered by the NEI network, obtain values for $M_{\mathrm{c}}$ ranging from 1 to 2.3 , and an overall $M_{\mathrm{c}} \sim 2.3$. A study applying the EMR method (Woessner \& Wiemer, 2005) on seismic sequences during the period 1977-2004 in the NEI area (Gentili and Bressan, 2008) reports a $M_{\mathrm{c}}$ ranging from 1.2 to 2.1 , dependent on the seismic sequence analyzed. Other recent analyses of the variation of $M_{\mathrm{c}}$ over time (Gentili et al. 2008, Gentili, 2010) show an increase of $M_{\mathrm{c}}$ from $0.5-1.5$ in the period $1977-1987$ to $1.5-2.5$ in $1988-$ 2007. All these studies refer to the conventional duration magnitude as given in the catalog.

In this paper, we use the Probability-based Magnitude of Completeness (PMC) method recently proposed by Schorlemmer and Woessner (2008): they derive, using empirical data only, completeness magnitudes $\left(M_{\mathrm{P}}\right)$ for given probability levels and detection-probabilities $\left(P_{\mathrm{E}}\right)$ for earthquakes of given magnitude. This method defines completeness as a function of station 
detection capabilities, which are derived from their respective picking performance, and network geometry. Therefore, this method allows for detailed analyses of detection probabilities and completeness magnitudes over space and time. In addition, because completeness is analyzed as a function of seismic network properties only, no event-size distribution is assumed as commonly done in methods based on the Gutenberg-Richter distribution.

The method consists of two major parts. First, detection-probability distributions per station are computed. They describe the probabilities of picking events with given magnitude at given distance to the station. The probability of detection at each station for a given magnitude-distance range is estimated by the ratio of the number of such located events picked at that station over the total number of such events located by the network during on-times of the station. Second, the detectionprobabilities at each station are synthesized into maps of detection probabilities $P_{\mathrm{E}}(M, x, y, z, t)$ of the network for specific magnitudes $M$, depth $z$ and time $t$, and into maps of completeness magnitudes $M_{\mathrm{P}}(P, x, y, z, t)$, for specific probability levels $P$. We obtain a probability distribution for each station, representing each station's performance during the chosen time span. Then, the regional maps of detection probability for a given magnitude and maps of probabilistic magnitude of completeness are computed by combining the single station detecting capabilities on a grid of points in the study area. The probability of detecting an event of given magnitude is the joint probability that the minimum number of triggering stations, $\mathrm{N}_{\mathrm{s}}$, (usually 4 , as minimum number of stations required by location procedures using only $\mathrm{P}$ phases, or 3 , as in our case, if $\mathrm{S}$ phases are used too) have detected it (see Schorlemmer and Woessner, 2008 for further details). Following Schorlemmer et al., (2010), we use a probability level of $P=0.999$ for computing the probabilitybased completeness magnitude $\left(M_{\mathrm{P}}\right)$, corresponding to a miss rate of one in one thousand events. Both, $P_{\mathrm{E}}$ and $M_{\mathrm{P}}$, are computed for a particular point in time. Because they are based on the station capabilities, only stations that were in operation at this particular time are considered in the computation. 
120

121

122

123

124

125

126

127

129

130

131

132

133

134

135

136

137

138

139

140

141

142

The PMC method has been applied to the Southern California Seismic Network (Schorlemmer and Woessner, 2008), the Northern California Seismic Network (Bachmann et al., 2007), Switzerland, (Nanjo et al., 2010b), Japan (Schorlemmer et al., 2008), and Italy (Schorlemmer et al., 2010). In particular, $M_{\mathrm{P}}$ for the Italian territory has been computed using data from the National Seismic Network; the analysis covers a short period from the start of the upgraded network at 16 April 2005 to 1 January 2008.

In this study we explore the results using the regional NEI seismic network inside the area $44.6^{\circ} \mathrm{N}-$ $47.2^{\circ} \mathrm{N} / 10.0^{\circ} \mathrm{E}-14.5^{\circ} \mathrm{E}$ which roughly corresponds to northeastern Italy. The long time span of the OGS catalog requires some ad-hoc $M_{\mathrm{D}}-M_{\mathrm{L}}$ calibration (see section 2.3) and constraints to avoid artifacts in the case of sparse data (section 3.1) and to improve the performance of the method.

\section{Data}

The data needed for the PMC method are an earthquake catalog describing the locations, times, magnitudes, and phase picks of events, and a station list containing location and working status (hereinafter referred as on-/off-times) of each station. Because the method can only be applied to periods of homogeneous recordings, which refers to unchanged trigger conditions, unchanged magnitude definitions, and unchanged processing, we first identified such periods of the NEI network.

The evolution of the NEI network (see Supplementary Online Material) can be roughly divided into four main periods (see also Marcellini and Milani, 2003; Priolo et al., 2005), characterized by different triggering conditions, seismic acquisition systems, and/or instrument characteristics.

$<$ Insert Figure 2 here>

Figure 2 shows the station distribution and locations of recorded events during each of the selected 
143

144

145

146

147

148

149

150

151

152

153

154

155

156

157

158

159

160

161

162

163

164

165

166

four periods:

- 6 May 1977-31 December 1987 (Figure 2a): recordings of analog data with continuous registration; up to 16 short-period seismic stations located in FVG and 6 in TN; events are detected by visual inspections of traces plotted by drum recorders; seismic phases were manually read from paper.

- 1 January 1988-5 May 1994 (Figure 2b): change from analog to digital acquisition system (Earth Data 9690); data are stored only if the trigger condition (set at individual station on the basis of signal-to-noise ratio exceeding a given threshold) is reached by at least three stations; initial slight increase in the number of stations (17 in FVG, 3 in VE, and 8 in TN). Since mid-1990, the 7 westernmost stations were operated by the Provincia Autonoma of Trento. The change from the analog to the digital system was gradually performed; as a result, during this period, phases were still manually read from paper, but with a lower resolution with respect to the previous analog data.

- 6 May 1994-31 December 1999 (Figure 2c): change of the digital acquisition system to Lennartz Mars 88 equipment; waveforms are stored for each individual station if the triggering condition is met at the respective station; nearly constant number of stations (17 in FVG, 4 in VE; no more TN triggering stations); manual digital data readings and set up of procedures for automatic picking (FAAS, Bragato and Govoni, 2000) and location. Bulletins report events after manual reprocessing. The first two broad-band stations were installed.

- 1 January 2000-31 December 2007 (Figure 2d): triggering conditions and acquisition data system as above with a general improvement of the performance of sensors; increase in the number of stations in the western part of the VE region (16 in FVG, 7 in VE) and installation of new broad-band stations. Fully digital processing of data. The original automatic alarm system (FAAS) is progressively replaced by procedures based on the Antelope software 
167

168

169

170

171

172

173

174

175

176

177

178

179

180

181

182

183

184

185

186

187

188

189 system. During this last period, a temporary network of 22 seismic stations in the Veneto (VE) region (see Figure 1) was active from May 2004 until June 2005 (FIRB-MIUR project - Govoni et al., 2005).

\subsection{Earthquake catalog}

All earthquake data used in this study are published in the monthly OGS bulletins and available on the OGS website (http://www.crs.ogs.trieste.it). The original data (published for many years on paper: OGS, 1977-now) is sporadically reprocessed to match with new standards or to increase homogeneity as far as location algorithms or magnitude computation are concerned (Renner, 1995).

The current OGS database includes 39,096 events in the period 6 May 1977-31 December 2007, of which 16,496 are located events with magnitude assignment. In case of non-located events, phase pickings and/or duration data of at least one station are stored if features of local events were recognized in manual inspections. These events are used for statistical characterization of microseismicity and are useful for further single-station studies. The HYPO71 location program (Lee and Lahr, 1975) is used for all the events with the same simple crustal model (three layers, with $v_{\mathrm{P}}=5.85,6.80$, and $8 \mathrm{~km} / \mathrm{s}$, and discontinuities at depths of $22 \mathrm{~km}$ and $39.5 \mathrm{~km}$, and $\left.v_{\mathrm{p}} / v_{\mathrm{S}}=1.78\right)$. Magnitudes are computed from duration data, using the station coefficients as calibrated by Rebez \& Renner, 1991.

The area covered by this analysis ranges from $10^{\circ} \mathrm{E}$ to $14.5^{\circ} \mathrm{E}$ in longitude and from $44.6^{\circ} \mathrm{N}$ to $47.2^{\circ} \mathrm{N}$ in latitude. Earthquake locations in the previously defined four main periods are reported in Figure 2; events with $M_{\mathrm{D}} \geq 3.5$ are represented by red dots, yellow stars show the $M_{\mathrm{D}}>5$ events.

The seismicity during the last 30 years of NEI monitoring was dominated by: 
190

191

192

193

194

196

197

198

- the activity following the 1976 devastating Friuli earthquakes (mainshocks plotted by white stars in Figure 1), which culminated in the seismic sequence of the 16 September 1977 Trasaghis earthquake $\left(M_{\mathrm{D}}=5.2\right.$, Slejko et al., 1999) (Figure 2a);

- the seismic sequences in Slovenia following the Kobarid earthquakes on 12 April 1998 and 12 July $2004\left(M_{\mathrm{D}}=5.6\right.$ in Figure 2c, and $M_{\mathrm{D}}=5.1$ in Figure 2d, Bressan et al., 2009);

- two earthquakes with $M_{\mathrm{D}}=5.2$, located at the margins of the monitored area, on 17 June 2001 in Merano (Caporali et al., 2005) and on 24 November 2004 in Salò (Franceschina et al., 2009) (Figure 2d);

- several minor seismic sequences in the period 1991-2002 with $M_{\mathrm{D}}$ from 3.7 to 4.9 , which lasted approximately 40-100 days (Gentili and Bressan, 2008) with numbers of recorded aftershocks ranging from 15 to 120 events.

The distribution of duration magnitudes over time is shown in Figure 3 together with some statistical and quality parameters of the hypocentral locations.

<Insert Figure 3 here>

One can recognize the increase from 1980 to 1998 of the lower magnitude thresholds and its decrease after 1998 in Figure 3a, and also the gap in 1991 (due to a fire accident in the data center of Udine city and its subsequent move to the current location at CRS in Cussignacco, monitoring activities were interrupted in the period from 4 December 1990 to 21 May 1991). The magnitude range in the period 1988-1994 appears to be squeezed, and during 1997-1999 the detection threshold reaches its highest value. The abrupt change in the number of located events that followed the dismantling of the analog system in 1989 and the effects of the seismic sequences in 1998 and 2004 are shown in Figure 3b. From the analysis of our dataset, we reckoned that most of these locations using less than seven phases (corresponding to a minimum number of four triggering stations using both $\mathrm{P}$ and $\mathrm{S}$ phases, represented by gray bars in Fig. $3 \mathrm{~b}$ ) were obtained by three 
214 stations only. The annual mean of phase picks per event (represented by black triangles in Figure

$2153 \mathrm{c}$,) pinpoints the evolution of the network, and it is only roughly representative of the quality of 216 location. The detection capabilities deteriorated with the transition from the analog to the digital 217 system and are improving since approximately the year 2000. Probably the occurrence of major 218 earthquakes (like the 1998 Kobarid sequence) has helped reorganizing the picking procedures, and 219 the latest upgrade of instruments further increased the number of readings per event. Horizontal and 220 vertical errors (ERH and ERV) as provided by HYPO71 are shown in Figure 3c: at a first glance 221 they widely change in time, but this is only the effect of a limited percentage of bad locations in a 222 great number of events pertaining to the first analog period (1977-1987), as their median values, 223 calculated on the whole catalogue, are 1.0 and $1.7 \mathrm{~km}$, respectively.

224 Fig. 3d shows the distribution of residuals between the station magnitudes, and the network 225 0.1 on the whole dataset, with negligible fluctuations in time.

\subsection{Station On/Off-times}

232 The official recorded information about failure or maintenance periods of single stations or the 233 entire network are usually very incomplete, often missing. Also, for the NEI network, these 234 informations are too inaccurate to be used in this application. For this reason, we estimate the 235 on/off-times directly from the phase picks. It is important to outline that pickings are reported in the 236 bulletins if features of regional events were recognized by manual inspections, even if the 237 respective event is not located, e.g. due to an insufficient number of phase picks for reliable 
locations. We therefore analyze for each station the cumulative number of phase picks over time and the inter-pick times between subsequent phase picks (see some examples in Figure 4).

<Insert Figure 4 here>

This simple technique permits easy recognition of random errors (e.g. mistypes in time when negative inter-pick times are encountered), changes in processing or working conditions (e.g. changes in the slope of the cumulative curve not linked to seismic crises), and random interruptions of recordings (inter-pick times exceeding a reasonable threshold). Pickings therefore testify the "in operation" (ON) status of the station, while out of work (OFF) conditions are more difficult to be detected, as earthquakes rates are variable in space and time. Note the good functioning of BOO and DRE stations, interrupted for more than 30 days only few times (the peak at $\sim 170$ days corresponds to the fire accident at the data acquisition center in 1991); DRE sensitivity with respect to the nearby Slovenian seismicity is evident by the plateau (increase in the daily number of detected events) corresponding to the 1998 e 2004 Kobarid sequences. AFL and MTLO show a more discontinuous functioning; very long interruptions ( $>240$ days), and changes of slope are related to different maintenance strategies for these stations.

After analyzing inter-pick times of all stations, and connecting the results with all independent information about recording conditions, we decided to fix a homogeneous threshold of inter-pick time to declare a station OFF. We performed sensitivity tests on different thresholds $(5,15,30,60$ and 90 days) to investigate the effects on the station detection probability and in the resulting completeness map during the period 2000-2007. For inter-pick time threshold larger than or equal to 30 days the mean completeness magnitude $M_{\mathrm{P}}$ of the studied area on 31 December 2007 remains essentially stable; for shorter thresholds, the mean $M_{\mathrm{P}}$ gradually increases with the threshold as the stations performances are evaluated only closed in time to detected phases, assigning therefore OFF 
262

263

condition also to "silence" due to non-detected earthquakes.

We therefore consider a station being $\mathrm{ON}$ if the inter-pick time is smaller than a threshold of 30 days. This threshold represents a compromise, tuned on the analyzed area, between the different background seismicity, and the lack of readings due to inactive stations.

\section{<Insert Figure 5 here>}

Figure 5 shows the synthesis of all the information concerning the on/off-times of OGS triggering stations from 1977 to 2007 , including the recording gap in 1991 due to the fire accident. A very discontinuous functioning can be observed for the stations CGRP, IESO, MGRP, MTLO, UDI, for AFL and FAU until 1999, for TLI since 2000, and for TRI since 1992. This is can be related to the very high noise level of stations (e.g. IESO, located in the alluvial plain close to the shore) and/or to different strategies in station maintenance. The shadowed rectangle shows TN stations activity during the period they were not managed by OGS; even if they were not used as triggering stations since mid 1990, their pick data were integrated in the catalog to increase location accuracy.

\subsection{Magnitude}

The OGS catalog reports duration magnitudes, homogeneously computed for the entire database by applying station corrections. These corrections have been calibrated for the first 21 OGS stations by Rebez and Renner (1991), applying a least-squares method to the general magnitude equation

$M=a_{1}+a_{2} \log T+a_{3} L$

where $M$ is the local magnitude at station TRI in Trieste (original Wood-Anderson data, or duration magnitude already calibrated to Wood-Anderson data), $T$ is the duration in seconds at the selected station, and $L$ the station-to-event epicentral distance in $\mathrm{km}$, and $a_{\mathrm{i}}$ are the station coefficients. 
285 Nearly all of the distance correction coefficients ( $a_{3}$ values) are very small (in the order of $\left.10^{-3}\right)$ and

286 their contribution to the attenuation term can be neglected. The original $M_{\mathrm{D}}-M_{\mathrm{L}}$ empirical 287 relationships for each station are defined in the range of $M_{\mathrm{L}}$ between 1.2 and 5.2; standard deviation 288 assigned to eq.(1) is station dependent, with a maximum of 0.35 . This is inter-event variability due 289 to multiple source-path-site effects and is greater that the intra-event variability described in Section 290 2.1. Station non-specific coefficients have been used for all the stations installed after 1988.

291 Bragato and Tento (2005) calibrated a regional attenuation relationship for local magnitudes, which 292 is valid for the network area, using high-quality digital data since 1995 and a Wood-Anderson filtering procedure. They demonstrated that duration magnitudes, $M_{\mathrm{D}}$, as obtained with the Rebez and Renner (1991) coefficients, largely overestimate local magnitudes, $M_{\mathrm{L}}$, for this period.

To convert duration magnitudes to local magnitudes for the application of the Schorlemmer \& Woessner (2008) completeness method, and to check the consistency of duration readings during the years, we investigate the original local magnitude and duration data for the periods 1977-1988 and 1995-2005. Technical problems quoted later on do not permit a similar analysis of the first digital period 1988-1995.

301 Figure 6a shows the local magnitude data from the Trieste station originally used by Rebez \& 302 Renner (1991) for calibrations of station coefficients plotted against the $M_{\mathrm{D}}$ values reported for the events in the OGS catalog. Local magnitude data comes from two datasets: 278 earthquakes with original Wood-Anderson recordings in the magnitude range 1.1-4.5 and 364 events with duration magnitude in the range $0.9-4.4$, recorded from 1977 to the beginning of 1988 , and converted to $M_{\mathrm{L}}$. The identity $M_{\mathrm{D}}=M_{\mathrm{L}}$ (green line) corresponds to the regression using a least-squares fit on the full

307 data set. In Figure 6b, a similar plot is given using the Bragato and Tento (2005) subset of events 308 (1096 earthquakes with local magnitude $M_{\mathrm{L}}$ in the range 0.8-5.5 recorded from 1995 to 2002), and 
an additional set of smaller events (169 earthquakes recorded by the FIRB network in the years 2004-2005, with $M_{\mathrm{L}}$ in the range of -0.1-3.2), similarly obtained by a filtering simulation of WoodAnderson magnitudes (Lovisa et al., 2008; Garbin, 2009); the inadequacy of $M_{\mathrm{D}}$ in reproducing $M_{\mathrm{L}}$ for $M_{\mathrm{D}}<3.5$ is evident.

Two main reasons can be identified for such a different behavior over time: the different rules in reading durations of seismic phases and the "drift" due to uncalibrated station coefficients. The readings in the first data set (1977-1988) were made on paper trails, while in the period 1995-2005 the readings were picked on the computer. It is reasonable to believe that the limited resolution of seismic waveforms on paper has lead to define shorter durations with respect to on-screen analyses, where much higher amplification factors can be applied to detect persisting seismic phases in the noise. This magnitude overestimation, with respect to the previous period, is amplified by station coefficients that were calibrated using paper trails.

Approximately from 1988 to 1994, digital data were plotted on paper for readings, but their resolution was lower than the one of analog data, possibly leading to shorter durations and subsequently to underestimated magnitudes (see Figure 3a). Unfortunately, the $M_{\mathrm{L}}$ dataset for this period is not adequate for $M_{\mathrm{D}}$ calibration; several technical problems (i.e. instrumental response and frequent spikes due to the electronic devices) are preventing a meaningful reprocessing. Also the use of uncalibrated station coefficients could affect the $M_{\mathrm{D}}$ computation. Because uncalibrated stations (those installed after 1988, see Fig. 5) are becoming increasingly important in magnitude determination, only further comparative analyses that are beyond the scope of this work could solve these problems of heterogeneous duration readings.

For our purposes, we decided to retain $M_{\mathrm{D}}=M_{\mathrm{L}}$ for pre-1988 earthquakes, based on the results shown in Figure 6a. We use the same rule for data from 1988 to mid-1994, as data were read from paper. For the period from mid-1994 on, we convert duration magnitudes, $M_{\mathrm{D}}$, into local 
333

334

335

336

337

338

339

340

341

342 period are computed. Only OGS triggering stations are considered as they are the only stations to

353 contribute to completeness. For the 4 th period, we integrate the catalog with the locations given by a magnitudes, $M_{\mathrm{L}}$, with the relation obtained through orthogonal regression

$$
\sigma\left(\mathrm{M}_{\mathrm{L}}\right)=0.35
$$


354

355

356

357

358

359

360

361

362

363

364

365

366

367

368

369

370

371

372

373

374

375

dense temporary local network to test the variation of completeness magnitude.

\subsection{Station detection-probability distributions}

The detection-probability distributions describe the probability of detecting earthquakes as a function of magnitude and distance from the station. To compute these distributions for each station, we need to apply the attenuation relation as used by the network, see Schorlemmer \& Woessner (2008) for details. We use the attenuation relation as provided by Bragato and Tento (2005) for northeastern Italy:

$M_{\mathrm{L}}=\log (A)+2.23 \log (L / 100)-0.0039(L-100)+3+S$

where $A$ is the amplitude of the signal, $L$ is the distance in $\mathrm{km}$ and $S$ is a station correction term; two events with equal amplitude at a station (and therefore with similar probability of detection) have a difference in magnitude that depends on their distances $L_{1}$ and $L_{2}$ from the station:

$\Delta M_{\mathrm{L}}=2.23\left[\log \left(L_{1}\right)-\log \left(L_{2}\right)\right]-0.0039\left(L_{1}-L_{2}\right)$

The distances axis can therefore be converted into a "magnitude" axis $M_{\mathrm{L}} *$ :

$M_{\mathrm{L}}^{*}=2.23 \log (L)-0.0039 L$

For computing the detection probabilities for events of given magnitude and given distance to the station, we apply the same criterion as described by Schorlemmer \& Woessner (2008).

This method of computing detection probabilities from raw data is robust as long as the number of earthquakes inside the sampling volume (here 0.1 magnitude units) is statistically significant.

An implicit assumption in choosing 0.1 magnitude units is that in such a small interval the magnitude distribution can be considered uniform. This is not true when the magnitude range is large, due to Gutenberg-Richter distribution. Therefore we maintain the sampling volume of the 
original method regardless of the larger uncertainty (see section 2.3) in the magnitude estimation in our catalogue.

Because some samples do not contain a sufficient number of events (set to 10), Schorlemmer and Woessner (2008) enlarge in a conservative manner the circular sampling volume towards larger distances and smaller magnitudes. We noticed that this choice can cause artifacts and/or overestimates of the performance in case of sparse data (see Figure 7 and related discussion).

We changed the original approach in a conservative way by setting the probabilities to zero for grid nodes with less than 10 events (Figure 8 and following text).

The original method applies a smoothing procedure that integrates basic physical constraints to reduce scatter due to sparse data and to remove non-physical artifacts. The algorithm guarantees that detection probabilities never decrease with increasing magnitude for a given distance and with decreasing distance for a given magnitude.

\section{$<$ Insert Figure 7 here>}

We computed detection-probability distributions ranging from 0 to 4 in magnitude and from 0 to $200 \mathrm{~km}$ in distance, matching the extension of the study area and the magnitudes of interest. Figure 7 shows the detection-probability distribution of station BAD derived using data from the period 7 May 1994-31 December 1999 and calculated according to the original PMC method. The color represents the detection probability. Where no data are available, the probability is set to 0 . Figs. $7 \mathrm{a}$ and $7 \mathrm{~b}$ represent the data before and after the smoothing procedure, respectively. One part of this distribution $\left(1.7<M_{\mathrm{L}}<2.8,50 \mathrm{~km}<D<180 \mathrm{~km}\right)$ is dominated by a noisy signal which we attribute to sparse data. The $P_{\mathrm{D}}=1$ contour in Figure $7 \mathrm{~b}$ shows a logarithmic trend of the minimum detectable magnitude for distances smaller than $100 \mathrm{~km}$, while a linear dependence becomes more relevant for $L>100 \mathrm{~km}$. This trend is compatible with equation 3 assuming that the minimum detectable amplitude at the station remains constant over time and is not dependent on earthquake 
400

401

402

403

404

405

406

407

408

409

410

411

412

413

414

distance. The $P=0.8$ contour departs from this trend for magnitudes $M_{\mathrm{L}}>1.8$, which is likely due to the previously outlined sparse data.

Therefore, before applying the smoothing procedure, we modified the original method as previously described to avoid possible artifacts related to sparse data.

\section{<Insert Figure 8 here>}

Figure 8 shows the normal and smoothed detection-probability distributions of station BAD for each of the four periods, applying the aforementioned new method. The best station sensitivity is reported for the analog period (Figs. $8 \mathrm{a}$ and $8 \mathrm{~b}$ ), which is characterized by continuous recordings. During the first digital period (Figs. $8 \mathrm{c}$ and $8 \mathrm{~d}$ ), the sensitivity decreased for small magnitudes. All events of $M_{\mathrm{L}} \geq 1.3$ seem to be detected by this station for distances lower than $40 \mathrm{~km}$ (see the abrupt change from $P=1$ to $P=0$ for this magnitude). This is compatible with the settings of the acquisition system (time series stored in memory only if at least three stations have reached the triggering conditions). For $M_{\mathrm{L}}>2$ and distances $>60 \mathrm{~km}$, the detection probability has an anomalous drop and gain (see the white rectangle in Figure 8c, where for a given magnitude the probabilities increase with distance). As a consequence, the network sensitivity has an abrupt jump at $M_{\mathrm{L}} \approx 2.2$ for distances of $50-100 \mathrm{~km}$ (compare Figs. $8 \mathrm{~b}$ and $8 \mathrm{~d}$ ) in the first digital period. The same effect has been detected for many other stations and may be related to problems of heterogeneous duration assignment in this distance/magnitude range that corresponds to data clipping on paperbacks. Combining the observations, we suggest that the narrower band of magnitudes represented in Figure 3a during the first digital period (1988-1994) is caused by two artifacts: first, the magnitude underestimation described in Section 2.3, and second, the higher detection threshold due to the acquisition limits. The observed behavior and the unavailability of data for an appropriate $M_{\mathrm{D}}-M_{\mathrm{L}}$ conversion from 1988 to 1994 make the detection-probability distribution for the first digital period less reliable than for the other periods; the derived 
completeness maps are therefore questionable.

Figs. 8e and 8 f show the detection-probability distributions for the second digital period. They show a similar sensitivity for small magnitudes and for large distances as the distribution for the analog period. In Figure 8e, two isolated clusters of high probabilities are highlighted by the white arrows, corresponding to cells where at least 10 earthquakes have been detected (compare to the features of the "noisy" area shown in Figure 7a). They have been similarly observed on other station graphs (e.g. BUA, BOO, PLRO), and they correspond to earthquakes scattered in time, but mainly located in Slovenia or Croatia, along major geological lineaments (striking $\mathrm{N} 120^{\circ}, \mathrm{N}_{150^{\circ}}$ ). Azimuthdependent heterogeneities due to lower crust characteristics, and/or waveguide effects driven by regional faults have been recently recognized (Bragato, pers. comm.; Garbin 2009), and they should cause signal amplifications with a magnitude scattering greater than 1 magnitude unit. Nevertheless, the study of azimuth-dependent effects is beyond the scope of this paper. Removing poorly sampled cells improves the performance of the smoothing procedure (compare Figs. 8e and $8 \mathrm{f}$ with Figs. 7a and $7 \mathrm{~b}$ ), but anomalies remain for $P<0.8$ in the 1994-1999 period. Figs. $8 \mathrm{~g}$ and $8 \mathrm{f}$ show the detection-probability distributions for the second digital period; the performances are similar to the previous ones, with a general decrease of anomalies and a slight improvement at low magnitudes. The higher number of events analyzed during 2000-2007 indicates a higher quality of data in Figure 8g than in Figure 8e.

The accurate analysis of the station detection probabilities in time allow to test the Schorlemmer and Woessner (2008) approach also in cases of scarce data. We impose a threshold on the minimum number of events in the node before the probability computation, reducing in this way the knowledge to the minimum. We show that with this procedure some artifacts are removed, before applying the smoothing procedure. This choice is conservative, because it increases the completeness magnitude at the end. 


\subsection{The effect of temporary monitoring}

450

451

The PMC method defines the station probability as the ratio of localized events detected by the station $\left(n_{\mathrm{S}}\right)$ over the number of events given in the catalog $\left(n_{\mathrm{C}}\right)$. The approximation accepted is that $n_{\mathrm{S}} / n_{\mathrm{C}} \approx N_{\mathrm{DS}} / N$, where $N_{\mathrm{DS}}$ is the number of events detected by the station and $N$ is the total number of earthquakes occurred. Using this approach, a catalog compiled by single station recordings (for example, the single station location procedures used by the pioneer seismological observatories) would result complete no matter what magnitude range would be considered, as $n_{\mathrm{S}}=N_{\mathrm{DS}}$ and $n_{\mathrm{S}}=n_{\mathrm{C}}$. We evaluate the role of missing events on station detection-probability distributions and on regional completeness-magnitude maps by integrating the OGS bulletins with a local catalog obtained by a temporary network. The FIRB-MIUR project (Govoni et al., 2005) installed a dense array of 22 portable seismic stations in an area of $60 \mathrm{~km}$ by $30 \mathrm{~km}$ in the Veneto (VE) region (see gray dots in Figure 1). The FIRB network was active from May 2004 until June 2005 and its data has been recently analyzed (Govoni et al., 2005, Garbin, 2009). The temporary network, jointly with the permanent OGS stations, enables us to locate 169 events, of which 132 were previously not detected. The event magnitudes are in the range 0.1-3.2. We investigate the effect on the detectionprobability distributions for the stations CGRP, CAE, FAU, and CSO, which are the triggering OGS stations closest to the FIRB network during the period the FIRB network was active (see Figs. 1 and 2d). The distribution of station CGRP is not affected by the new dataset, while station CSO (see Figure 9) shows a predominant decrease in detection probabilities for magnitudes in the range 1-2.2 associated with an increase of the localized earthquakes in the FIRB catalogue that are not registered by the station.

\section{<Insert Figure 9 here>}

A small increase for distances less than $30 \mathrm{~km}$ was observed for stations CAE and FAU, showing the ability of these stations to detect also such small events. The ability to detect is hidden by the small 
473

474

475

476

477

478

479

480

481

482

483

484

485

486

487

488

489

490

491

492

493

494

495

496

number of earthquakes available in that magnitude-distance range in the OGS bulletins (where station picks can exist without associated earthquake locations) which strictly depends on the network configuration. These changes in detection-probability distributions have only minor effects on the completeness maps (see also Section 4). Similar results have been found for the Italian National Seismic Network by Schorlemmer et al. (2010).

\section{Results}

We computed detection-probability and completeness maps for the NEI region using $0.05^{\circ}$ spacing in latitude and longitude at a depth of $10 \mathrm{~km}$, because the seismicity in this area is mainly concentrated between 8 and $12 \mathrm{~km}$ depth. The NEI network starts locating events if three or more stations trigger (by using P and S picks, see Figure 3 and related discussion), hence we set $N_{\mathrm{s}}=3$ for computing the detection probabilities $P_{\mathrm{E}}$.

\section{$<$ Insert Figure 10 here>}

Figure 10 shows snapshots of the probability-based magnitude of completeness, $M_{\mathrm{P}}$, for the NEI network over time, computed using the respective detection-probability distributions as obtained for the four periods previously described. The completeness magnitude is expressed in terms of local magnitudes. We use the OGS catalog for all maps, except for Figure 10e where FIRB locations are included.

The analog period (May 1977-December 1987) was characterized by different network configurations. In the first years, the monitored area was only the FVG region, and we observe completeness magnitudes, $M_{\mathrm{p}}$, in the range from 1 in the inner part to 2 at the border of FVG (see the completeness map at 30 December 1980 in Figure 10a). After 1983, several stations have been added in the FVG region and the TN seismic network was installed. As a consequence, the completeness magnitude decreases (see the completeness map for 28 December 1985 in Figure 10b) 
497

498

499

500

501

502

503

504

505

506

507

508

509

510

511

512

513

514

515

516

517

518

519

520

521

not only inside the areas covered by the stations (up to 1.5 magnitude units approximately), but also in the regions between the two sub-networks; the northern part of the VE region shows an $M_{\mathrm{P}}$ of 2 which increases to 2.5 southwards.

During the period January 1988-May 1994, the TN network became independent, the acquisition system of the NEI network changed from analog to digital, and continuous recording was replaced by recording only waveforms if at least three stations had triggered. This choice, acceptable for alarm purposes, strongly limits the number of located events, as no further control or data integration with non-real-time stations is possible. These changes resulted in lower sensitivity of the network (see Figure 3). Figure 10c shows the completeness map at 5 January 1988, a time when the TN network was still active. The limitations in data acquisition and storage during this period are causing a loss in completeness, visible in the reduction of $M_{\mathrm{P}}<1.5$ areas. As a result, completeness during this period is more tightly controlled by the geometry of the three nearest stations. Comparing with the previous period (Figure 10b), the higher sensitivity of the network at large distances from the stations during the first digital period (Figure 10c) is an artifact due to the anomalous drop and gain of the station probability distributions (described in Figs. 8c and 8d).

Therefore, we believe that this map is not reliable. As a consequence, we suggest that analysts should focus their attention on the "inner" quality of detection-probability distributions and on their consistency with other observations (e.g. magnitude vs. time plots).

In the following period, May 1994-December 1999, a one-station triggering condition was used but the sensitivity remained lower than during the analog period. Figure $10 \mathrm{~d}$ shows $M_{\mathrm{P}}$ values of the network at 31 December 1997, when all the stations in VE region were off. The NEI authoritative area was reduced to the FVG region, similarly to what had happened in 1980 (Figure 10a); see the similar sized region characterized by $M_{\mathrm{P}} \leq 1.5$. Due to the larger number of stations and to their more homogeneous spatial distribution, the area with $M_{\mathrm{P}}<2.3$ is now larger with respect to Figure 10a. 
522

523

524

525

526

527

528

529

530

531

532

533

534

535

536

537

538

539

540

541

542

543

544

545

The last studied period (January 2000-December 2007) was characterized by a gradual extension of the network westwards, toward the VE region. Figure 10f shows the network performance at the end of the period (31 December 2007). Due to the development of the seismic network, in most parts of the $\mathrm{VE}$ and the TN regions completeness magnitudes are at least 2.5 , reaching 2 in the northern part of the VE region. From 2008 on, the TN region network, being managed again from OGS, is increasing the coverage of both the TN and the VE regions.

Figure 10e shows the effect of merging the OGS bulletins with the FIRB-MIUR database for 1 September 2004. Here, a significant enhancement of $M_{\mathrm{P}}$ can be observed, a well pronounced lobe of $\mathrm{M}_{\mathrm{P}}<1.5$ covers the southwestern part of the region surveyed by the temporary stations.

The role of missed events in the OGS bulletins on the station probability distributions analyzed in section 3.2 (see Figure 9) has a low impact on $M_{\mathrm{P}}$ map computed for the off-time of the FIRB temporary network (on 31 December 2007): differences were observed and were in the order of 0.1/-0.2 magnitude units, comparable with the error in magnitude assessment.

The PMC method has been applied to the INGV network covering the national territory since 16 April 2005 (Schorlemmer et al., 2010).

We compared OGS and INGV local magnitude earthquakes assessments for the overlapping period (16 April 2005-31 December 2007) in order to evaluate the networks performances for the area under study.

A total number of 176 events were analyzed, the selection criteria used to identify common OGS and INGV events being a difference in latitude and longitude smaller than 0.1 degrees and a difference in origin time smaller than 10 seconds in the respective catalogues. The results of the orthogonal regression shows good correlation between the two magnitude assessments, given by

$\mathrm{M}_{\mathrm{L}(\mathrm{INGV})}=0.88 \mathrm{M}_{\mathrm{L}(\mathrm{OGS})}+0.19$

$$
\sigma\left(\mathrm{M}_{\mathrm{L}}\right)=0.27
$$

and eq. 6 crosses the identity line $\mathrm{M}_{\mathrm{L}(\mathrm{INGV})}=\mathrm{M}_{\mathrm{L}(\mathrm{OGS})}$ at about $\mathrm{M}_{\mathrm{L}} 1.5$, the value chosen to compare 
the performances. We highlight that the station concurring to the $\mathrm{M}_{\mathrm{L}} \mathrm{s}$ estimate are different for the

547 two networks.

$<$ Insert Figure 11 here>

549 Figure 11a shows detection probabilities of the INGV network (for $M_{\mathrm{L}}=1.5$ ) on 1 January 2008 at a 550 depth layer of $30 \mathrm{~km}$, as derived from Schorlemmer et al. (2010). Green regions correspond to 551 probabilities close or equal to 1 , while white regions correspond to probabilities equal to 0 . Figure $55211 \mathrm{~b}$ shows our results for the NEI network at the same time and depth so that the results can be 553 directly compared. Note that all the other maps were computed for a $10 \mathrm{~km}$ depth layer. The NEI 554 network shows detection probabilities for $M_{\mathrm{L}}=1.5$ close to unity for a large part of the FVG Region 555 (see Figure 11b); it is decreasing westward (Veneto region) and toward the coastline. Considering 556 the fact that our study only use triggering stations to compute $P_{\mathrm{E}}$ and $M_{\mathrm{P}}$ (therefore TN stations were not considered operational at 1 January 2008, see Figure 2 and Figure 5) and that some conservative changes to the original method have been applied, the comparison shows that the regional network managed by OGS fills the gap in detection probabilities $\left(P_{\mathrm{E}}\right.$ less than 0.5 for $\mathrm{M}_{\mathrm{L}}=1.5$ ) as computed for the INGV network (Figure 11a).

\section{Conclusions}

563 We analyzed the NEI seismic network performance during the past 30 years using the PMC method

564 (Schorlemmer \& Woessner, 2008). This method does not assume any event-size distribution (e.g. 565 Gutenberg-Richter, 1944), and is based only on data recorded at stations. It allows to investigate on 566 spatio-temporal variations of completeness.

567 The network sensitivity can be calculated day-by-day, according to the on/off times of the stations, 568 with an high (in our case approximately $5 \mathrm{~km}$ ) spatial resolution; such resolution permits to 
569

570

571

572

573

574

575

576

577

578

579

580

581

582

583

584

distinguish areas characterized by different $M_{\mathrm{P}}$, depending on the seismic network characteristic. This is particularly important in areas where the capabilities of a network are strongly heterogeneous over space and time.

In the OGS catalogue, the analysis permits to recognize that the most seismic active region (North FVG) of the area under study was always characterized by a $M_{\mathrm{P}}$ of approximately 1.5 during the four analyzed periods. The minimum of the completeness magnitude is always reached in such an area. Others regions (e.g. VE, TN) are characterized by higher $M_{\mathrm{P}}$ values, that varies depending on the analyzed period.

These differences should be properly considered when performing seismic analysis studies in NE Italy. In fact a whole catalogue analysis (using e.g. EMR or Maximum Curvature methods) leads to a wrong completeness magnitude evaluation, overestimated in the case of FVG and that could be underestimated in the case of VE regions and TN, due to the smaller statistical relevance of such regions data.

An $M_{\mathrm{P}}$ overestimation can lead to a looses of data and statistical relevance of the results, e.g. for b value estimation; in the case of the seismicity variation analysis (quiescence/increased seismicity studies), some relevant features could be lost due to the lack of low magnitude earthquakes in the input dataset. On the other end, underestimation can significantly bias the estimation of b values, seismicity rates, etc, and this can have important effects on extracting a model of seismic activity, useful for hazard estimation, like e.g. simulating seismic quiescence (see Wiemer e\& Wyss 1994).

The OGS network covers the northeastern part of Italy and is in operation since 1977. We analyzed the performance for four distinct periods from 1977 to 2007 . We show the different performance of the NEI network over time and space, with focus on the important differences between analog and digital recording periods.

The analog system, operating approximately from 1977 to 1988, shows the highest sensitivity; 
593

594

595

596

597

598

599

600

601

602

603

604

605

606

607

608

609

610

611

612

613

614

615

616

617

manual readings on continuous recordings resulted in the best detection capability observed at this network. However, such analyses require extensive manual data processing. This observation is interesting and was found also in Nanjo et al 2010a, especially considering that many other networks also changed from analog to digital signal processing. The first bulk of stations in the FVG region were installed to detect the seismicity in the epicentral area of the $1976 \mathrm{M}=6.4$ earthquake. After 1981, a second group has been installed in the TN region (Figure 2a), which is about $150 \mathrm{~km}$ away from the epicentral area. The effect of joint operation of both groups of stations is evident from our results (Figure 10b). The sensitivity of this regional network was improved for the entire northeastern part of Italy for the period 1982 to 1990 in which the TN stations were used as triggering stations for the NEI network.

In contrary to this period of high-quality recordings, the subsequent period of digital signal processing is characterized by a strong decrease in the number of located events accompanied by an increase of the minimum magnitude threshold. We interpret this observation as a decay of detecting capabilities due to well known technical problems in the acquisition procedures and the real-time data storage. Furthermore, we identified a potential systematic bias in magnitude assignments. Regression analyses of the $M_{\mathrm{D}}-M_{\mathrm{L}}$ dataset are suggesting different criteria in duration pickings on paperbacks and on-screen signals (Figure 6). Because the $M_{\mathrm{D}}-M_{\mathrm{L}}$ calibration for the period 1988 1994 period was not feasible, we applied the relationship derived for the analog period (i.e. $M_{\mathrm{D}}=M_{\mathrm{L}}$ ), obtaining anomalies in the detection-probability distributions of the stations (Figs. 8c and $8 \mathrm{~d}$ ). These anomalies cause low $M_{\mathrm{P}}$ values at more than $50 \mathrm{~km}$ distance from the stations (Figure 10c), such that we cannot consider the results for this period reliable. Fixing these problems would require a huge reprocessing of the original waveforms that is beyond the purpose of this analysis.

With the start of the new digital acquisition system (Lennartz Mars88) in 1994-1995, the network coverage decreased. Not only the TN stations became independent after 1990, but also the signal-tonoise threshold was increased to limit real-time data transmission. Some high-detection 
618 probabilities during the period 1994-1999 (arrows in Figure 8e) are blurred in the following period

619 2000-2007 (Figure 8g). A first check suggests that they are not artifacts, but physically motivated

620 propagation anomalies, following the direction of major lineaments, and therefore azimuth-

621 dependent effects. We obtain more reliable detection probabilities for each station by imposing a

622 threshold on the minimum number of events in the node before the probability computation (Figs.

$6237,8 \mathrm{e}$, and 8f). Since 2000, the gradual enlargement of the NEI network and improvements in

624 sensors performances is enhancing the sensitivity of the network and extending the coverage to a 625 wider area.

626 With the configuration at 31 December 2007, the completeness magnitude reached values below $627 M_{\mathrm{L}}=2.3$ in parts of the VE region, in the FVG region, and neighboring countries (Figure 10f).

628 These results should be discarded considering the uncertainty in $M_{\mathrm{P}}$ due to the inter-event 629 variability. From 2008 on, the TN region network is being managed again by OGS, and this, 630 together with the new VE stations installed in 2007 and 2008 (BALD and ADRI, respectively), is 631 improving again the network performance for the western areas. With increased quality control of 632 broad-band OGS stations, and more data readings we expect further enhancements. When a 633 database large enough to obtain stable results will be available, a further work will quantify this 634 improvement.

635 Even if it is beyond the scope of this paper to give an estimate of the impact of this new way of 636 representing completeness magnitude on seismic activity estimates, we do expect significantly 637 different estimates in areas where the network geometry has changed in time and space. As an 638 example, in this work we explored the integration of a dense temporary network with the NEI 639 network and show the remarkable decrease of the completeness magnitude that such an integration 640 induces locally.

641 A comparison with a study conducted for the overall Italian national territory (Schorlemmer et al., 
642 2010) shows that the NEI regional network is able to ensure in the active region of NE Italy

643 earthquake detection capabilities better than the performances of the National Seismic Network.

644 The NEI network, therefore, fruitfully complements the seismic monitoring capability of the

645 National Seismic Network. It is important to point out that our evaluation covers about 30 years of

646 monitoring, while the INGV analysis is limited to the last acquisition system, operating since 16

647 April 2005 (Schorlemmer et al., 2010).

648 The OGS bulletin data, the station parameter table, and the software codes used for this study are

649 freely available on the completeness web site http://www.completenessweb.org/. A Matlab code for 650 the application of this method to California and Italian data of the INGV seismic network is freely 651 available at the same web site.

652

653 Acknowledgements

654 The NEI Network is financially supported by the Civil Protection of the Regione Autonoma Friuli

655 Venezia Giulia, and of the Regione Veneto, and by the Geological Service of Provincia Autonoma 656 di Trento. We thank the technical staff of the Dipartimento Centro di Ricerche Sismologiche (OGS)

657 for data acquisition and processing. In particular, we want to thank the open-source community for

658 the Linux operating system and the many programs used in this study. Maps were created using

659 GMT (Wessel \& Smith, 1991). The work was supported by NSF-EAR-0738785 grant. This research

660 was supported by the Southern California Earthquake Center. SCEC is funded by NSF Cooperative

661 Agreement EAR-0529922 and USGS Cooperative Agreement 07HQAG0008. The SCEC 662 contribution number for this paper is 1326.

663 
664

665

666

667

668

669

670

671

672

673

674

675

676

677

678

679

680

681

682

683

684

685

686

\section{References}

Antonelli, A., Bragato, P. L., Braitenberg, C., Bressan, G., Carulli, G.B., Costa, G., Marson, I., Nichelini, A., Ordine Regionale dei Geologi del Friuli-Venezia Giulia, Peruzza, L., Quendolo, A., Riuscetti, M., Sgobino, F., Slejko, D., Suhadolc, P., Verri, G., Zadro, M., 2000. Cronistoria di un terremoto. Carulli, G.B., ed. Guida alle escursioni Escursione B4 9-10settembre, TIPOGRAFIA, Trieste, 293-340.

Bachmann, C., Schorlemmer, D., Kissling, E., Oppenheimer, D., 2007. Probabilistic Magnitude of Completeness of the Northern Californian Seismic Networks Strategies for Reducing Data Flaws (Abstract). Seismol. Res. Letts. 78, 292.

Bragato, P. L., Govoni, A., 2000. The Friuli automatic earthquake alert system. Boll. Geof. Teor. Appl., 41, 59-77.

Bragato, P. L., Tento, A., 2005. Local Magnitude in Northeastern Italy. Bull. Seism. Soc. Am., 95, $579-591$.

Bressan, G., Gentile, G. F., Perniola B., Urban S., 2009. The 1998 and 2004 Bovec-Krn (Slovenia) seismic sequences: aftershock pattern, focal mechanisms and static stress changes. Geophys. J. Int., $179,231-253$.

Caporali, A., Braitenberg, C., Massironi, M., 2005. Geodetic and hydrological aspects of the Merano earthquake of 17 July 2001. Journal of Geodynamics, 39, 317-336.

Castellaro, S., Mulargia, F., Kagan Y. Y., 2006. Regression problems for magnitudes. Geophys. J. Int., 165, 913-930.

Franceschina, G., Pessina, V., Di Giacomo, D., Massa. M., Castellano, S., Mulargia, F., Mucciarelli M., 2009. La ricostruzione dello scuotimento del terremoto del Garda del 2004 (ML = 5.2). 
687

688

689

690

691

692

693

694

695

696

697

698

699

700

701

702

703

704

705

706

707

708

709

710

Bollettino della Società Geologica Italiana, 128, 217-228.

Garbin, M., 2009. Predisposizione, riordino e archiviazione delle elaborazioni dati sismometrici relativi alle stazioni temporaneee delle reti Ravedis e Firb. REL.OGS 2009/64 CRS 6 APSES dd. 23/04/2009.

Gentili S., Bressan, G., 2007. Seismicity patterns before MD>= 4.1 earthquakes in the FriuliVenezia Giulia (northeastern Italy) and western Slovenia areas. Bollettino di Geofisica Teorica ed Applicata 48, 33-51.

Gentili, S., Bressan, G., 2008. The partitioning of radiated energy and the largest aftershock of seismic sequences occurred in the northeastern Italy and western Slovenia. Journal of Seismology, $12,343-354$.

Gentili, S., Sugan, M., Peruzza, L., 2008. Completezza probabilistica della magnitudo per l'Italia Nord-Orientale. REL.OGS 2008/92 CRS 13 APSES dd. 15/07/2008

Gentili, S., 2010. Distribution of seismicity before the larger earthquakes in Italy in the time interval 1994-2004 Pure Appl. Geophys. 167, 933-958.

Govoni, A., Anselmi, M., Ascione, E., Chiarabba, C., Chiaraluce, L., Colasanti, G., Gentili, S., De Gori, P., Di Bartolomeo, P., Moretti, M., Romanelli, M., Valoroso, L., 2005. Studio della micrisismicità lungo la linea Bassano-Valdobbiadene-Vittorio Veneto: Esperimento AlpagoCansiglio 2004-2005. Gruppo Nazionale di Geofisica della Terra Solida, 24 Convegno Nazionale, Roma, 15-17 November 2005, 37-39.

Gutenberg, B., Richter C. F., 1944. Frequency of earthquakes in California, Bull. Seism. Soc. Am. $34,185-188$.

Lee, W. H. K., Lahr J. C., 1975. Hypo 71 (revised): a computer program for determining hypocenter, magnitude and first motion pattern of local earthquakes. U.S.G.S.: Menlo Park. p. 113.

Lomax, A., 2001. SeisGram2K, http://alomax.free.fr/seisgram/SeisGram2K.html, Editor. 
711 Lovisa, L., Garbin, M., Peruzza, L., 2008. Distribuzione spazio-temporale dei terremoti registrati 712 nel vallone bellunese Gruppo Nazionale di Geofisica della Terra Solida, 27 Convegno Nazionale, 713 Trieste 6-8 October 2008, pp. 158-159.

714 Marcellini, M., Milani, D., 2003. Valutazione della sismicità temporale del Friuli-Venezia Giulia. 715 Internal Report CNR Istituto per la dinamica dei processi ambientali, Milan, Italy.

716 Morelli, C., 1959. L'Osservatorio Geofisico Sperimentale di Trieste, Bollettino di Geofisica Teorica 717 e Applicata, 1, 3-26.

718 Nanjo, K. Z., Ishibe, T., Tsuruoka H., Schorlemmer, D., Hirata, N., Ishigaki, Y., $2010 a$. 719 Completeness Study for the JMA Catalog: A Baseline for Rigorous Tests of Earthquake Forecasts 720 for Japan 3rd SCEC-ERI joint workshop, 16-17 March 2010, Tokyo, Japan.

721 Nanjo, K. Z., Schorlemmer, D., Woessner, J., Wiemer, S., Giardini, D. 2010b. Earthquake detection 722 capability of the Swiss Seismic Network. Geophys. J. Int. 181, 1713-1724.

723 OGS; 1977-1981: Bollettino della Rete Sismologica del Friuli-Venezia Giulia. Monthly report, 724 OGS, Trieste

725 OGS; 1982-1990: Bollettino della Rete Sismometrica dell'Italia Nord orientale. Monthly report, 726 OGS, Trieste

727 OGS; 1991-..: Bollettino della Rete Sismometrica del Friuli-Venezia Giulia. Monthly report, 728 www.crs.inogs.it

729 Priolo, E., Barnaba, C., Bernardi, P., Bernardis, G., Bragato, P. L., Bressan, G., Candido, M., 730 Cazzador, E., Di Bartolomeo, P., Durì, G., Gentili, S., Covoni, A., Klinc, P., Kravanja, S., 731 Laurenzano, G., Lovisa, L., Marotta, P., Nichelini, A., Ponton, F., Restivo, A., Romanelli, M., 732 Snidarcig, A., Urban, S., Vuan, A., Zuliani, D., 2005. Seismic monitoring in Northeastern Italy: a 733 ten-year experience. Seismological Research Letters, 76, 451-460.

734 Rebez, A, Renner, G., 1991. Duration magnitude for the northeastern Italy seismometric network. 
735

736

737

738

739

740

741

742

743

744

745

746

747

748

749

750

751

752

753

754

755

756

Boll. Geof. Teor. Appl., 33, 177-186.

Renner, G., 1995. The revision of the Northeastern Italy seismometric network catalogue. Bollettino di Geofisica teorica e applicata, Supplement to Vol XXXVII n. 148, 329-505.

Scherbaum, F., Johnson, J., 1992. PITSA, Programmable Interactive Toolbox for Seismological Analysis. IASPEI Software Library, Vol. 5. Lee, W. (ed.), 189pp

Schorlemmer, D., Hirata, N., Euchner, F., Ishigaki, Y., Tsuruoka, H., 2008. SCEC Annual Meeting, Palm Springs, USA 9 September 2008.

Schorlemmer, D., Mele, F., Marzocchi, W., 2010. A Completeness Analysis of the National Seismic Network of Italy. J. Geophys. Res., 115, B04308, doi:10.1029/2008JB006097

Schorlemmer, D., Woessner, J., 2008. Probability of Detecting an Earthquake. Bull. Seism. Soc. Am., 98, 2103-2117.

Slejko, D., Neri, G., Orozova, I., Renner, G., Wyss, M., 1999. Stress field in Friuli (NE Italy) from fault plane solutions of activity following the 1976 main shock. Bull. Seism. Soc. Am., 89, 10371052.

Wessel, P., Smith, W. H. F., 1991. Free software helps map and display data. Eos Trans. AGU, 72(441), 445-446.

Wiemer, S., Wyss, M., 1994. Seismic quiescence before the Landers (M 7.5) and Big Bear (M 6.5) 1992 earthquakes. Bull. Seism. Soc. Am., 84, 900-916.

Woessner, J., Wiemer S., 2005. Assessing the Quality of Earthquake Catalogues: Estimating the Magnitude of Completeness and Its Uncertainty. Bull. Seism. Soc. Am., 95, 684-698. 
Map of the study area, with administrative borders and seismic station locations. Acronyms of Italian region are as follows: FVG, Regione Autonoma Friuli Venezia Giulia; VE, Veneto; TN, BZ Provincia Autonoma di Trento e Bolzano respectively; LO, Lombardia; ER, Emilia Romagna.

Black symbols and labels mark the seismological networks managed by OGS at 2008; broad-band (BB) and short-period (SP) stations are represented using hexagons and triangles respectively. Gray triangles indicate all the other stations listed in the NEI bulletins database during the period from 6 May 1977 to 1 January 2008 (dismissed OGS locations, or belonging to other institutions, see the text). Gray circles show the location of a temporary network (22 FIRB stations), deployed in May 2004.

The locations of the disastrous 1976 Friuli earthquakes $\left(M_{\mathrm{L}}=6.4\right.$ and 6.1, Slejko et al. 1999) are 772 also shown with white stars.

Figure 2

Network geometries and seismicity distribution in time. Grey dots mark earthquakes with $M_{\mathrm{d}}<3.5$, red ones for $3.5 \leq M_{\mathrm{d}} \leq 5.0$, yellow stars for events with $M_{\mathrm{d}}>5$. Black and gray triangles indicate triggering and not triggering stations, respectively. (a) Analog period, the number of stations gradually increased in time (TN stations since 1981); (b) first digital period, triggering stations changed in time (from $1990 \mathrm{TN}$ stations became independent); (c) change in the acquisition system 
780

781

782

783

784

785

786

787

788

789

790

791

792

793

794

795

796

797

798

799

800

801

802

and data storage of the second digital period; (d) time frame corresponding to a more stable network configuration, and enhancement of station sensors and quality controls. Further details on stations functioning in Figure 4 and 5.

Figure 3

Synthetic overview of NEI bulletins database; more than 16,000 events have been located with magnitude assignment in the period 6 May 1977-31 December 2007. (a) Duration magnitude distribution versus time (dotted, solid and dashed lines are the $5^{\text {th }}, 50^{\text {th }}$ and $95^{\text {th }}$ percentile of the data, calculated at steps of one year); (b) histograms of located events per year (black bars, total number; grey bars, number of events located with less than 7 phases); (c) quality check of hypocentral solutions: mean annual number of phases per event (black triangles, right y-axis), vertical and horizontal errors in km (black and grey dots, left y-axis); (d) distribution of magnitude residuals (difference between the station magnitudes and the network magnitude). See the text for more details.

\section{Figure 4}

Examples of station's activity status. Cumulative number of pickings versus time (left y-axis) and intertimes between pickings (delay, right y-axis) for four stations (see location in Figure 1): (a) BOO, in central FVG; (b) DRE nearby the Slovenia border; (c) ALF in northern VE; (d) MTLO in central VE region.

\section{Figure 5}


803

804

805

806

807

808

809

810

811

812

813

814

815

816

817

On-off times of the OGS stations: a station is considered on (black traits) if not signed out of work in the station book, and if the intertime of two consecutive pickings is less than 30 days. Stations of the TN region are on top of the graph, marked with an asterisk: the gray rectangle highlights the period when TN stations went into independent management, performed by the Provincia Autonoma di Trento; even if the phases have been somehow used for the final bulletins, these stations cannot be considered triggering stations for the OGS network.

\section{Figure 6}

Regression analysis of duration versus local magnitude. (a) original dataset from 1977 until 1988, used by Rebez and Renner (1991) to calibrate station coefficients: MWA is the original Wood Anderson magnitude given at the Trieste (TRI) station, MD TS are duration magnitude at the same station, used as reference values if MWA were not available. (b) new data recorded from 1995, local magnitude is obtained by simulating the Wood Anderson response from digital data: MWA Bragato is the dataset published by Bragato and Tento (2005), MWA FIRB is the dataset of the temporary monitoring of FIRB Project (Govoni et al., 2005). Duration magnitudes (x-axis) are those reported in the NEI bulletins. Green lines represent the $M_{\mathrm{D}}=M_{\mathrm{L}}$ condition, black and red full lines are respectively the least squares (lsq) and orthogonal (or) regression relationships on the whole dataset (all), dashed lines the orthogonal regression on partial data (black and gray).

\section{Figure 7}

Probability graph for BAD station during the period 7 May 1994-31 December 1999. Detection probabilities on a magnitude versus distance plane is calculated using the original PMC method, without (a) and with (b) the smoothing procedure. Color scale ranges from blue ( $0 \%$ probability of detection) to red (100\% probability of detection). The white arrow shows anomalous corner in 
827 probability curves due to scattered cells of high probability at $\sim 110 \mathrm{~km}$ distance. Dashed line

828 represents the $P=0.8$ contour.

829

$830 \quad$ Figure 8

831 BAD station detection-probability distributions, with modified settings: the probability is put to 0 if

832 less than 10 events are detected in the search area. Probabilities are computed for four different time 833 periods (rows), without and with (left and right column, respectively) the application of smoothing 834 procedure.

835 (a), (b): analog period (1977-1987); (c), (d) first digital period (1987-mid 1994), the white 836 rectangle underlines an anomalous pattern in magnitude versus distance detection capability, 837 tentatively explained by non homogeneous duration lectures (see the text); (e), (f) second digital 838 period (mid 1994-1999, old network configuration), note the reduction of artifacts, with respect to 839 Figure 7, but some high probability cells still survive: the white arrows point at groups of 840 earthquakes for which azimuth dependent effects have been suggested; (g), (h) second digital period 841 (2000-2007, actual network configuration). Color scale as in Figure 7.

Figure 9

845 Differences in the smoothed detection probabilities for CSO station for the whole period 2000846 2007, using the OGS bulletins integrated with the FIRB temporary network earthquakes (from May 8472004 until June 2005) and events reported in the OGS bulletins only. Blue and red regions show 848 respectively the decrease and increase in detection probabilities. The first one is due to the increase 849 of the localized earthquakes in the FIRB catalogue that are not registered by the station; the second 
850

851

852

853

854

855

856

857

858

859

860

861

862

863

864

865

866

867

868

869

870

871

872

873

one represents earthquakes registered by the CSO station but that have been localized only thanks to the FIRB network.

Figure 10

Maps of probabilistic magnitude of completeness obtained using $0.05^{\circ}$ grid spacing and a reference depth of $10 \mathrm{~km}$. White triangles are stations in operation at the date of computation. Magnitude color scale ranges from yellow $\left(M_{\mathrm{P}}=1\right)$ to blue $\left(M_{\mathrm{P}}=3\right)$, in white the cells where no computation has been performed. (a), (b) maps referred to the analog period, computed for 30 December 1980 and for 28 December 1985, respectively; the installation of TN stations ensures an acceptable completeness in VE region, too. (c) Map computed for 5 January 1988 referred to the first digital period: we do not retain this picture a reliable result (reasons in the text). (d) Map computed for 31 December 1997, referred to the new digital system; at this date all VE stations were off, the TN stations independently managed and therefore no triggering stations of the OGS network anymore; network performances cover more homogeneously the FVG region with respect to (a). (e) Map computed for 1 September 2004, merging OGS bulletins with FIRB catalogue; this map includes 18 temporary stations (gray triangles), active that date, and shows their role on local detection completeness. (f) Map computed for 31 December 2007, referred to the more stable network configuration.

\section{Figure 11}

Detection probabilities maps for $M_{\mathrm{L}}=1.5$ on 1 January 2008; (a) Seismometric National Network of INGV, NE Italy (modified from Schorlemmer et al., 2010); (b) Regional networks of OGS, NE Italy (this study). Maps are computed at a reference depth of $30 \mathrm{~km}$. Triangles are the stations in operation at that date. Color scale is the same for the two figures, ranging from white $(0 \%$ 
874 probability to detect an earthquake of $\left.M_{\mathrm{L}}=1.5\right)$ to green $(100 \%$ probability to detect it).

875 


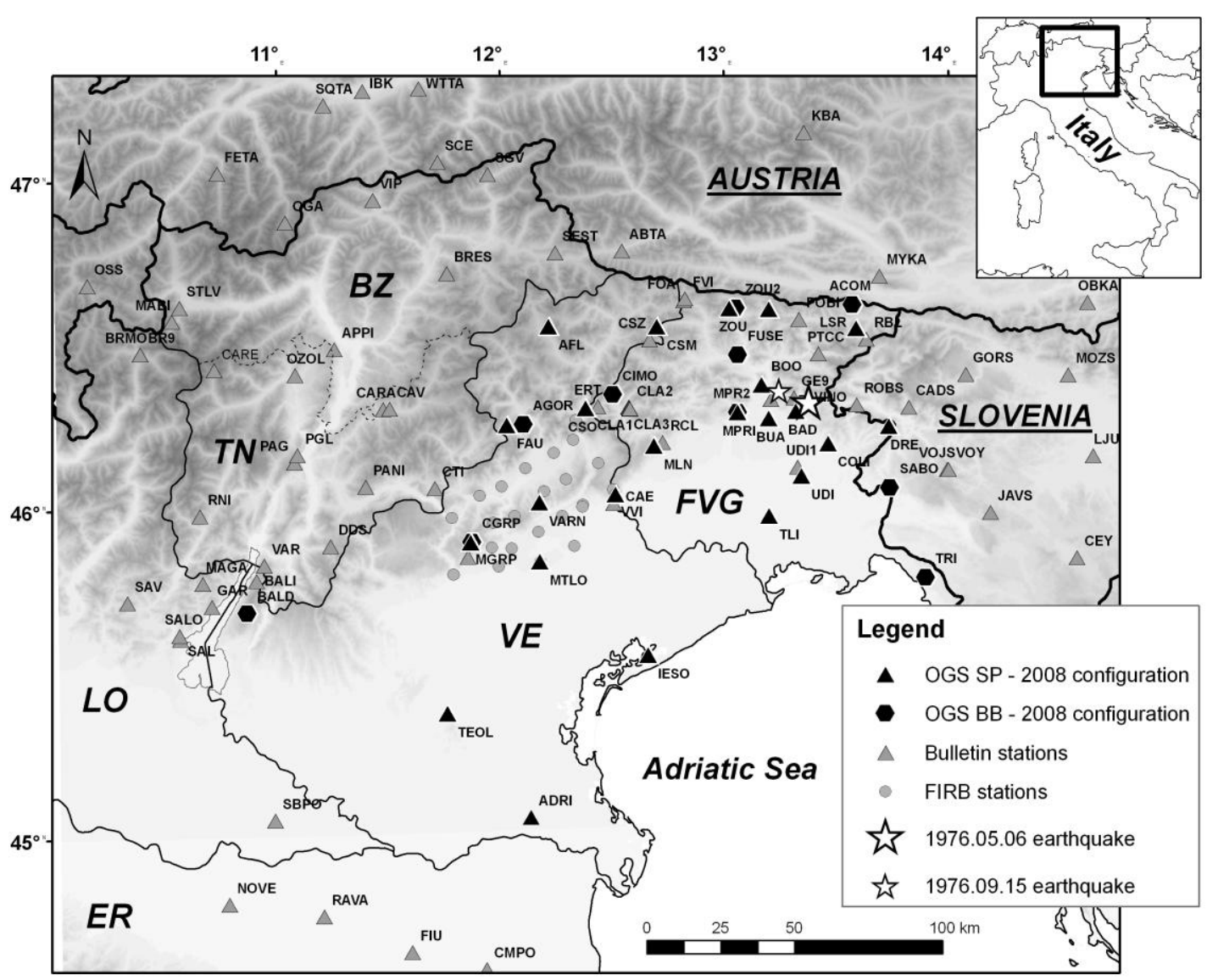

Fig. 1
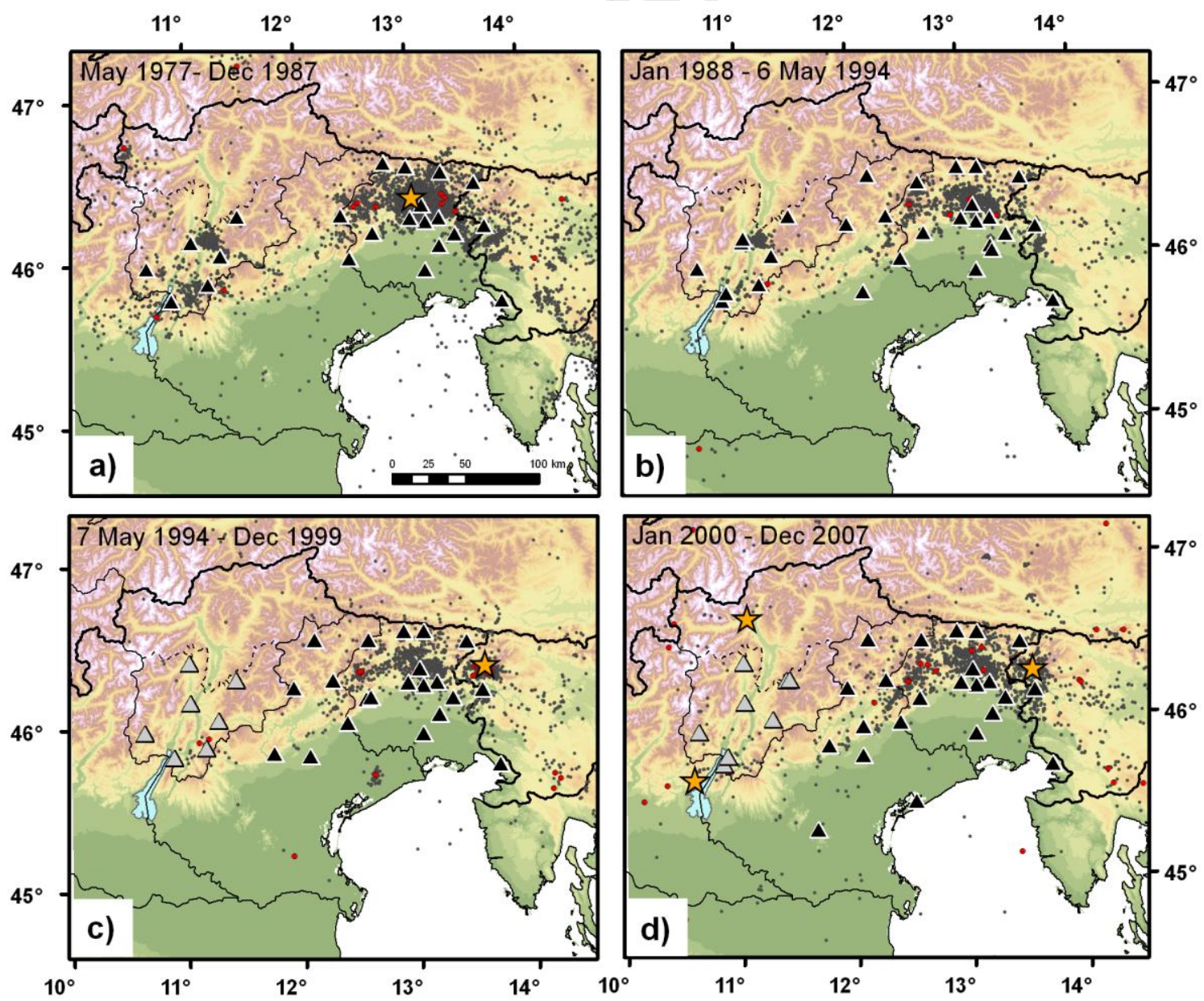

Fig. 2 


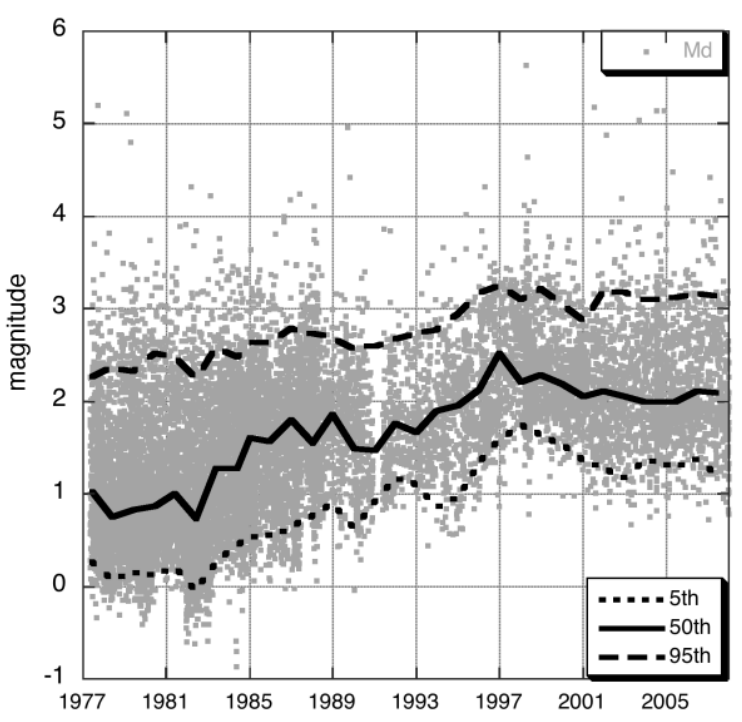

(a)

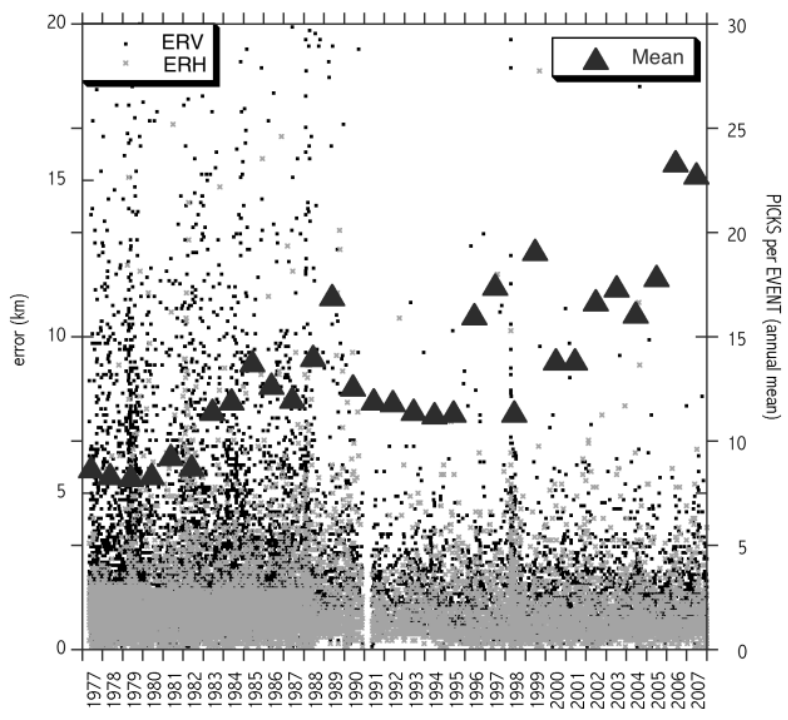

(c)

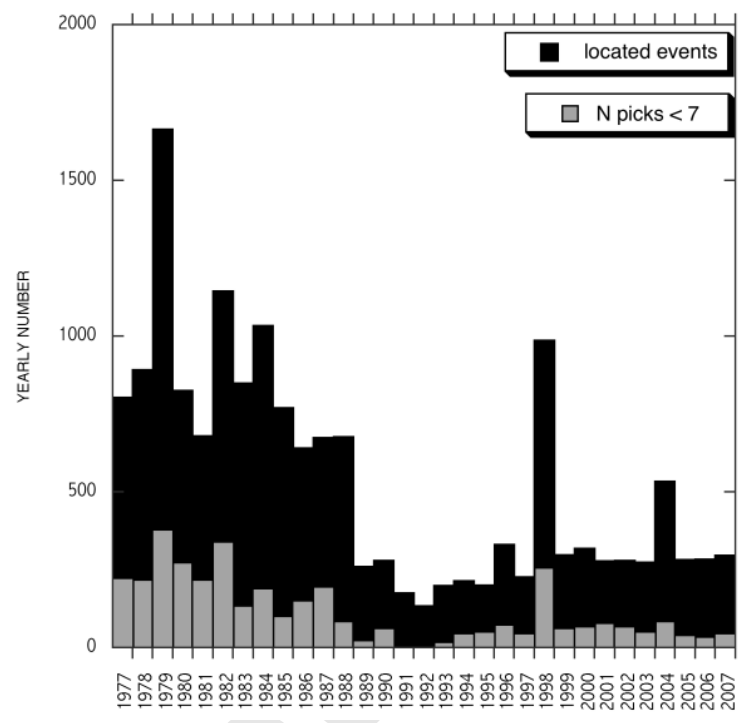

(b)

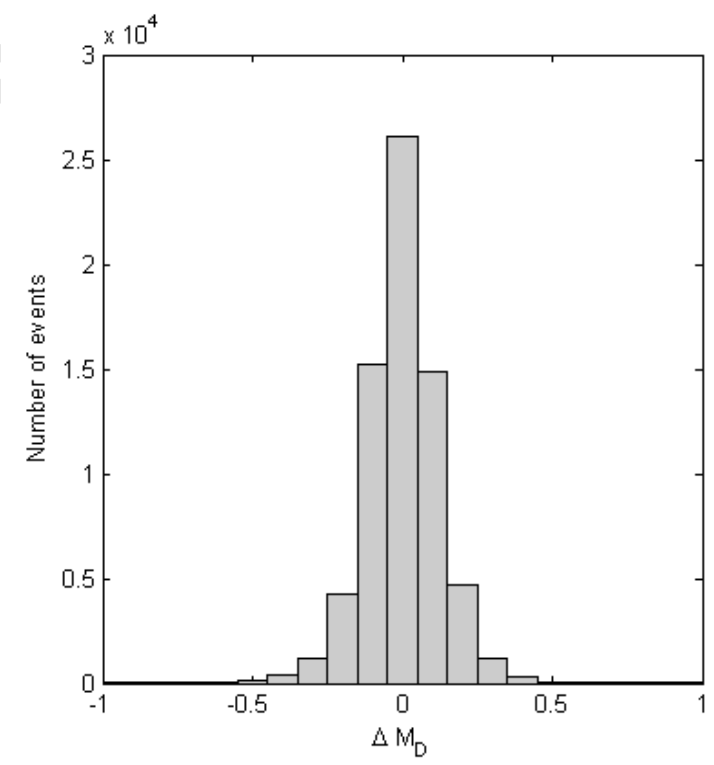

(d)

Fig. 3 


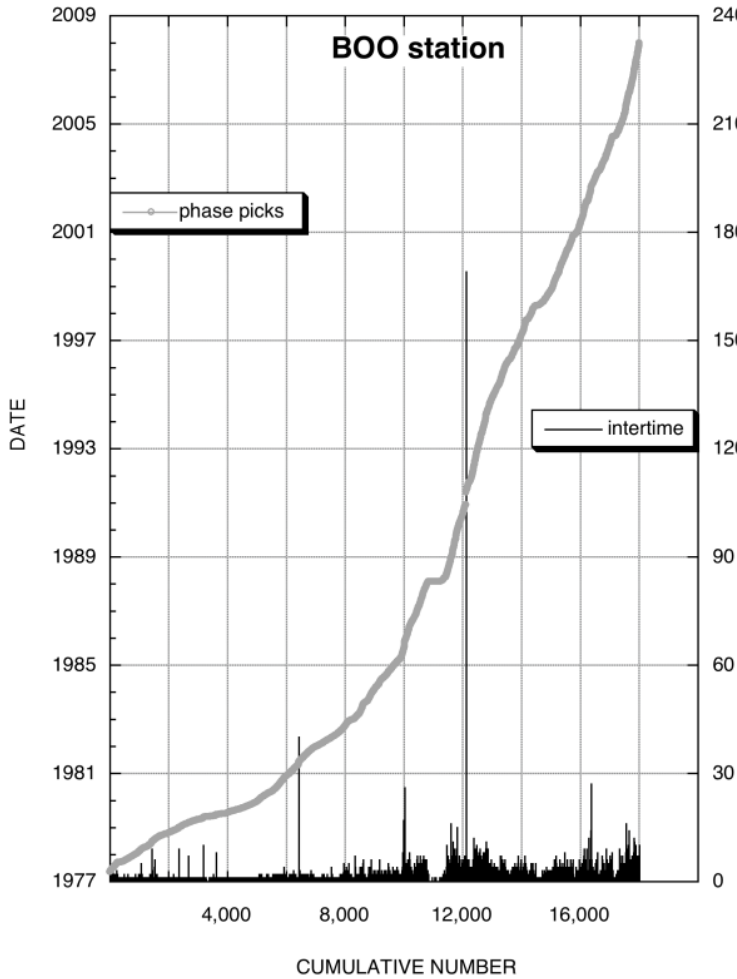

(a)

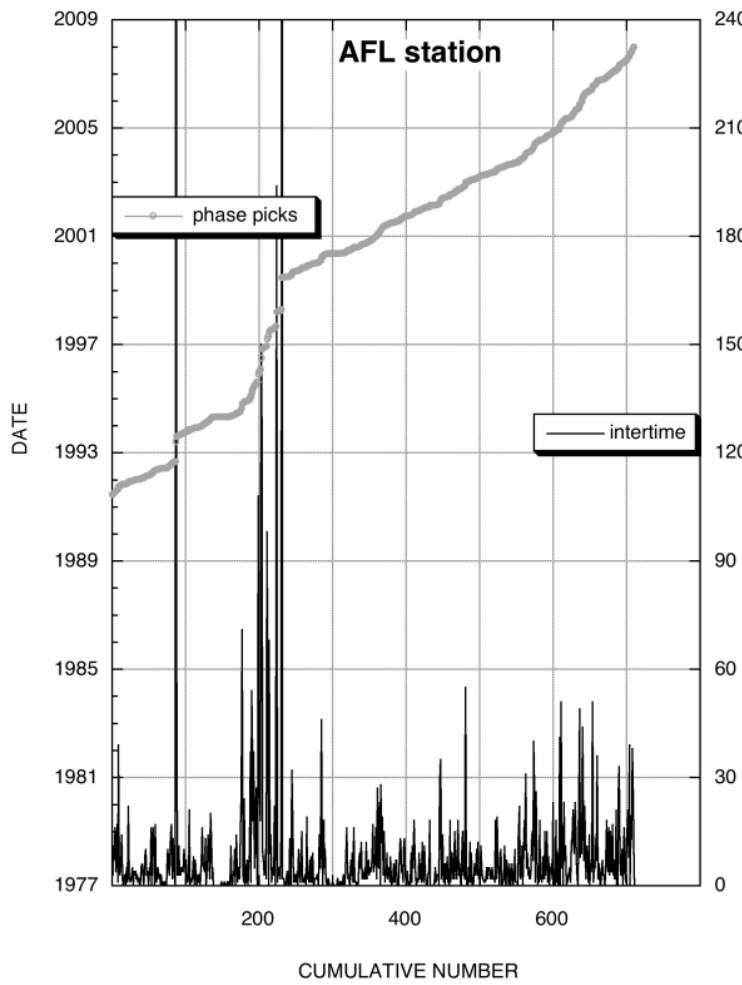

(c)

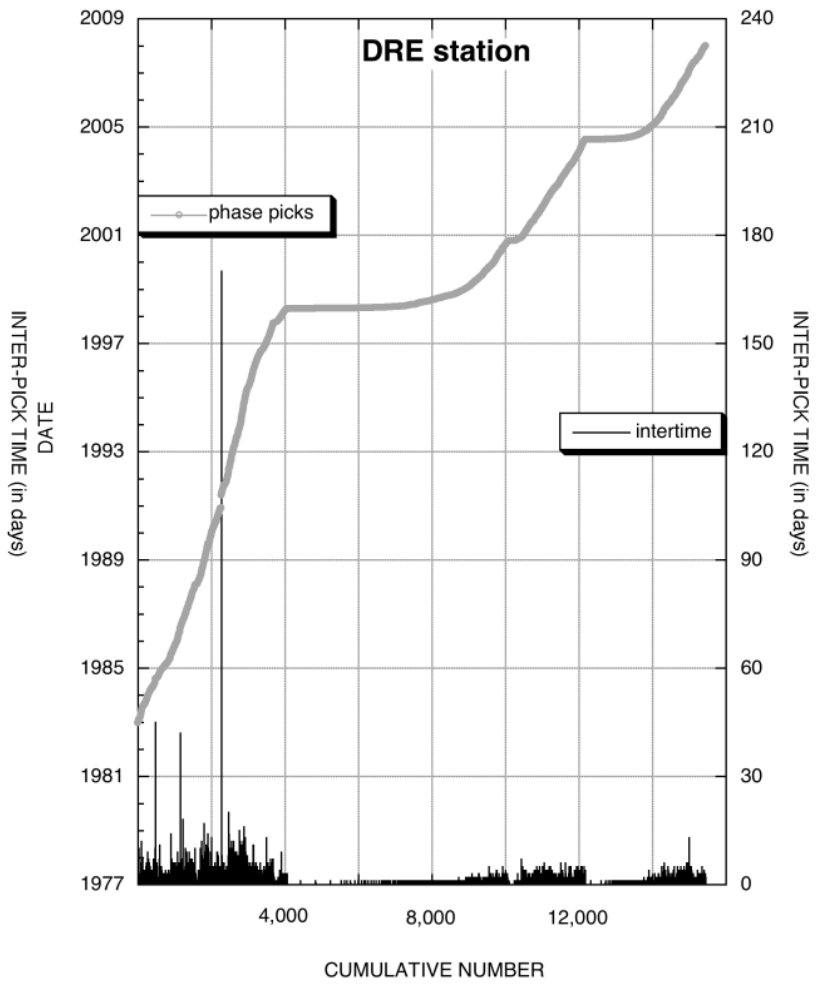

(b)

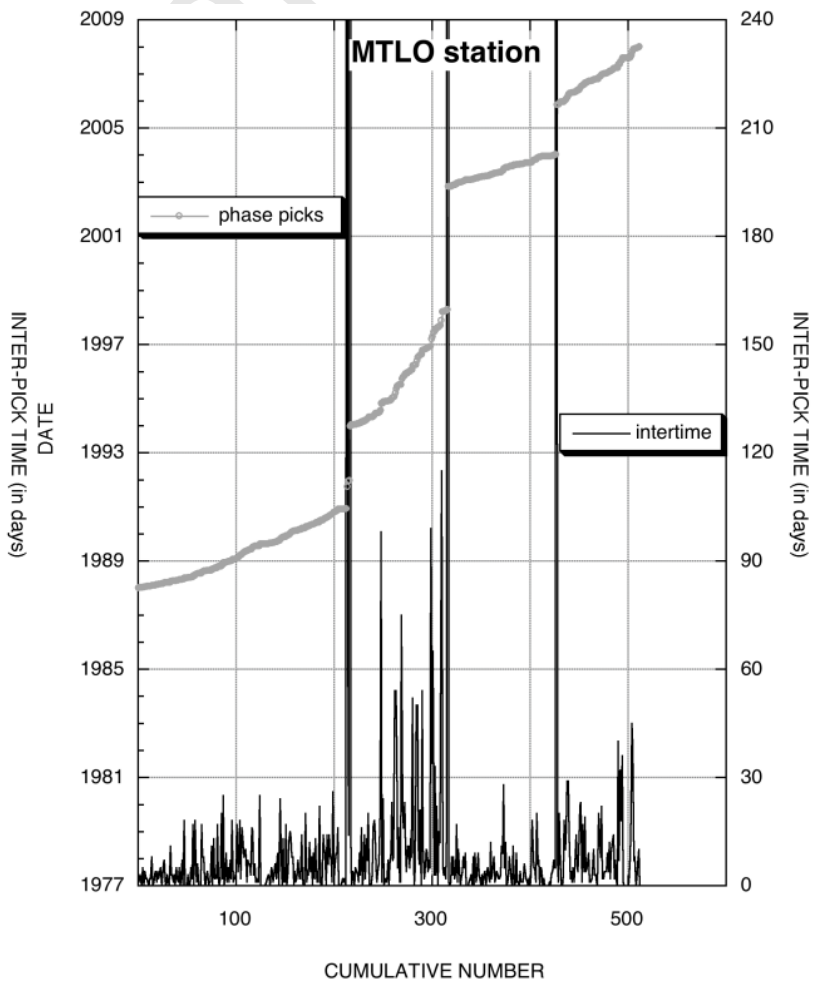

(d)

Fig. 4 


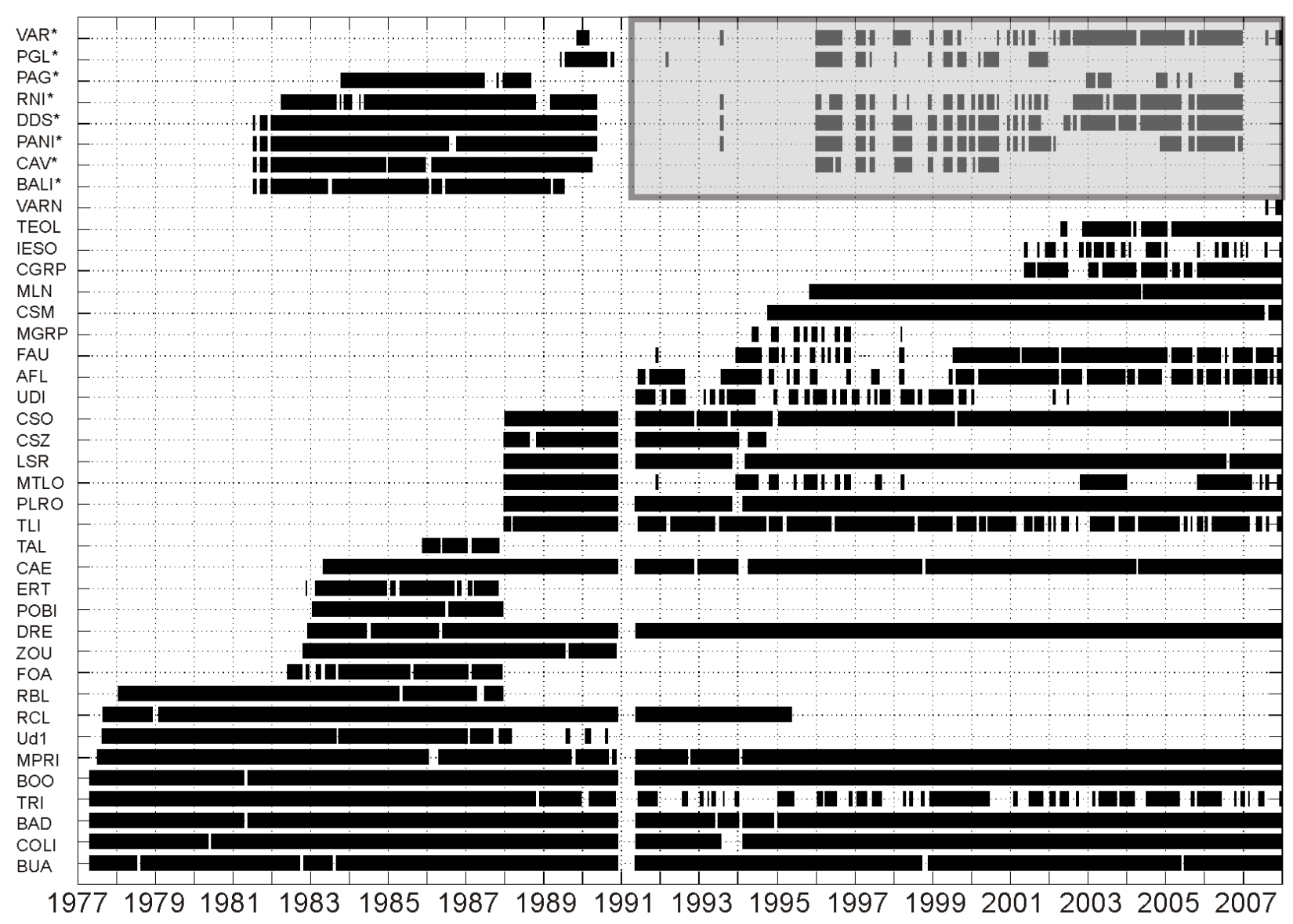

Fig. 5

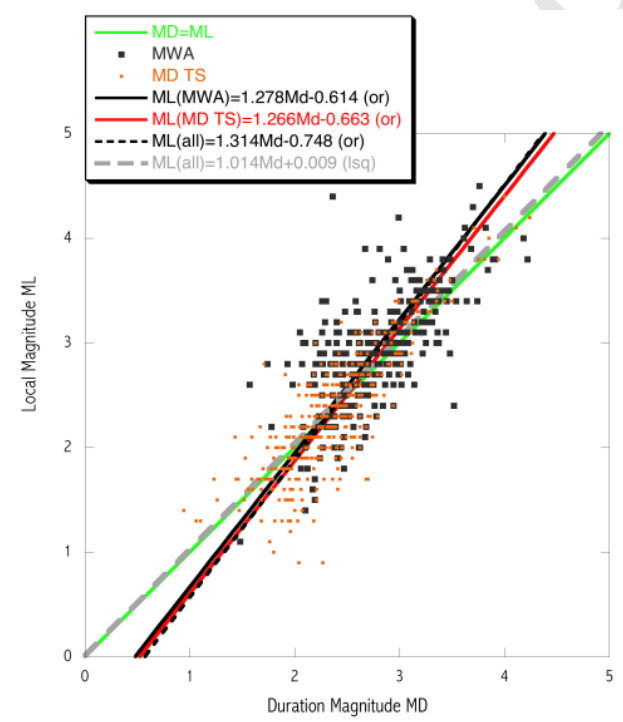

(a)

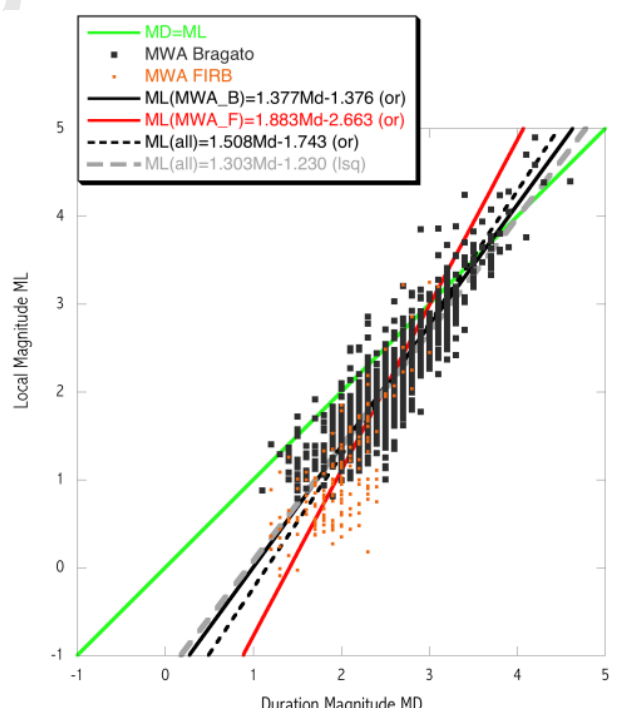

(b)

Fig. 6 


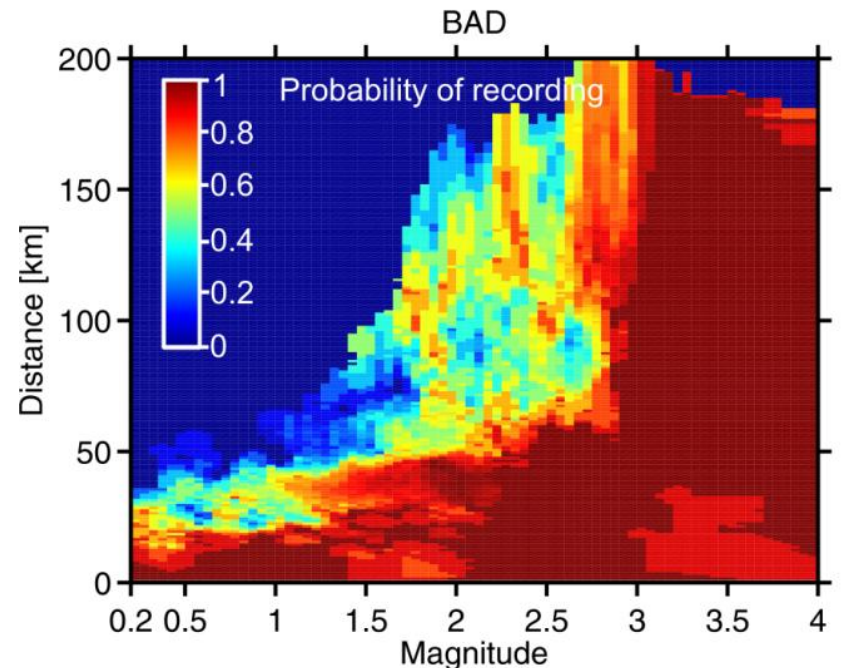

(a)

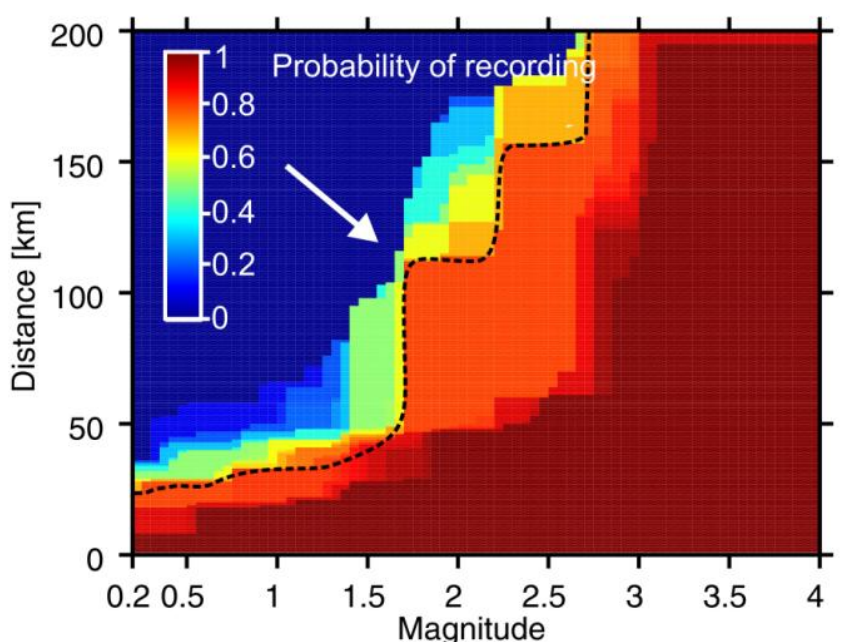

(b)

Fig. 7

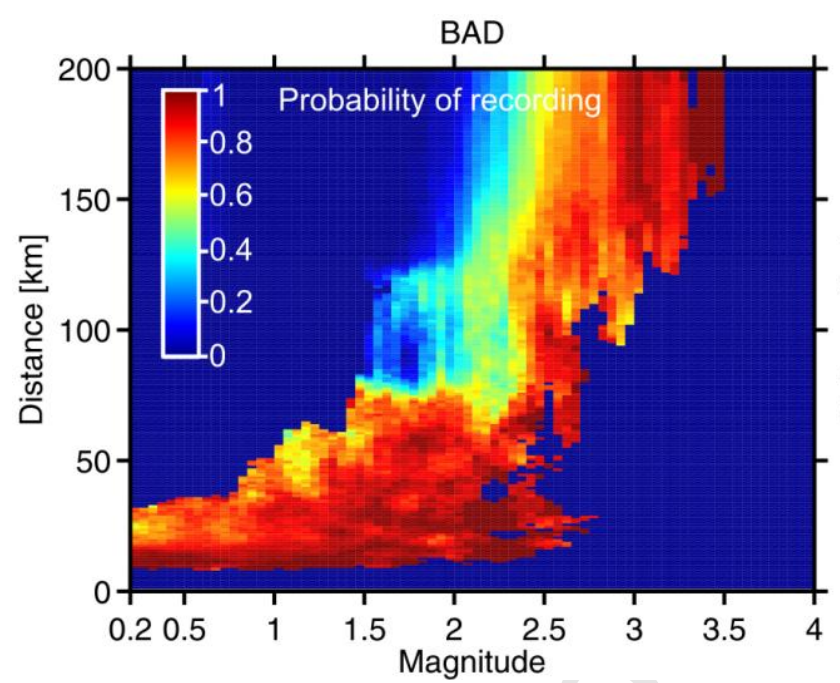

(a)

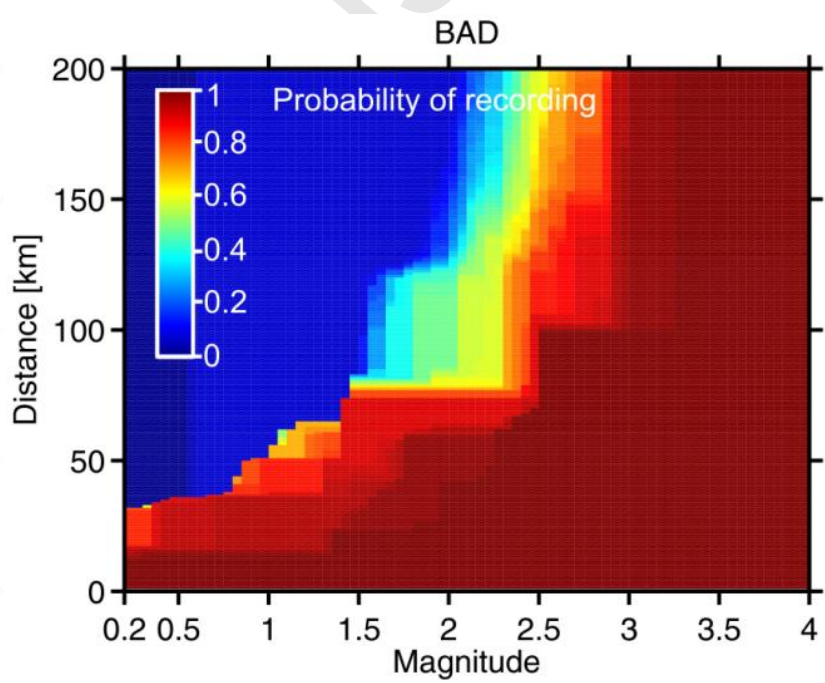

(b)

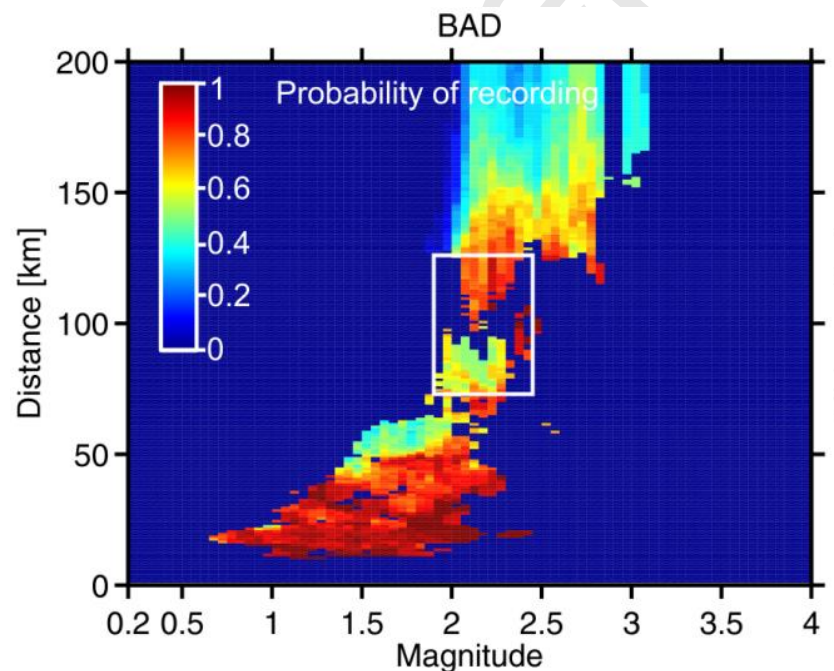

(c)

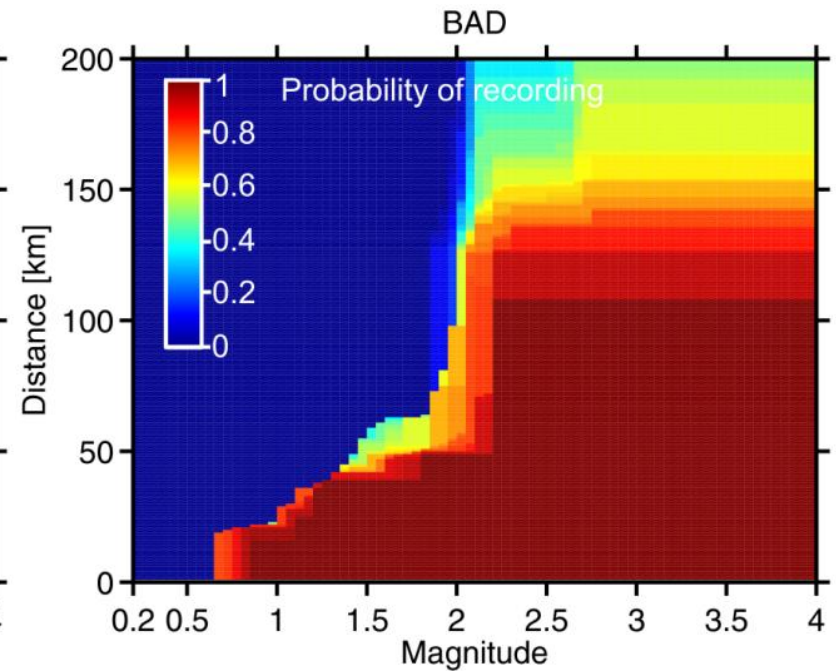

(d) 


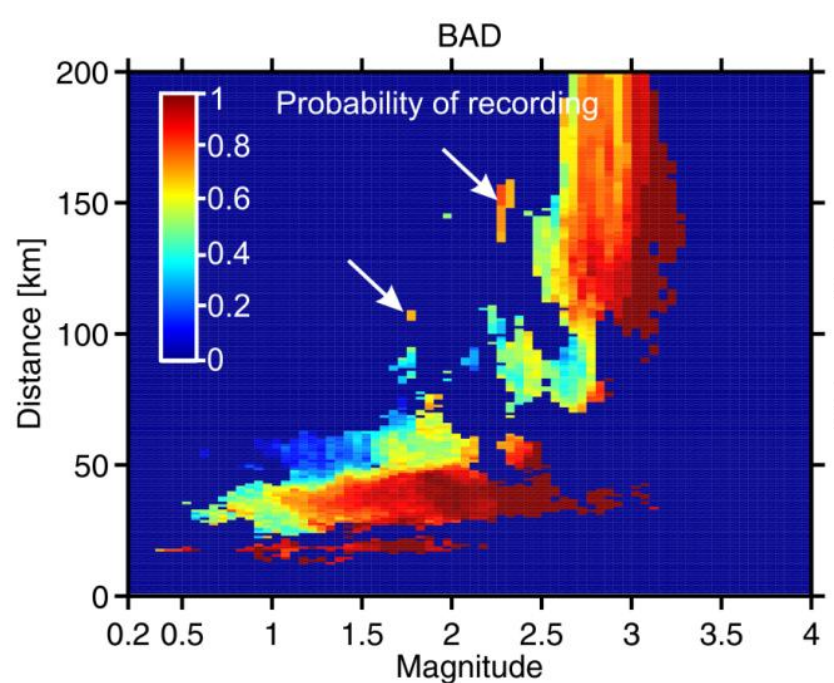

(e)

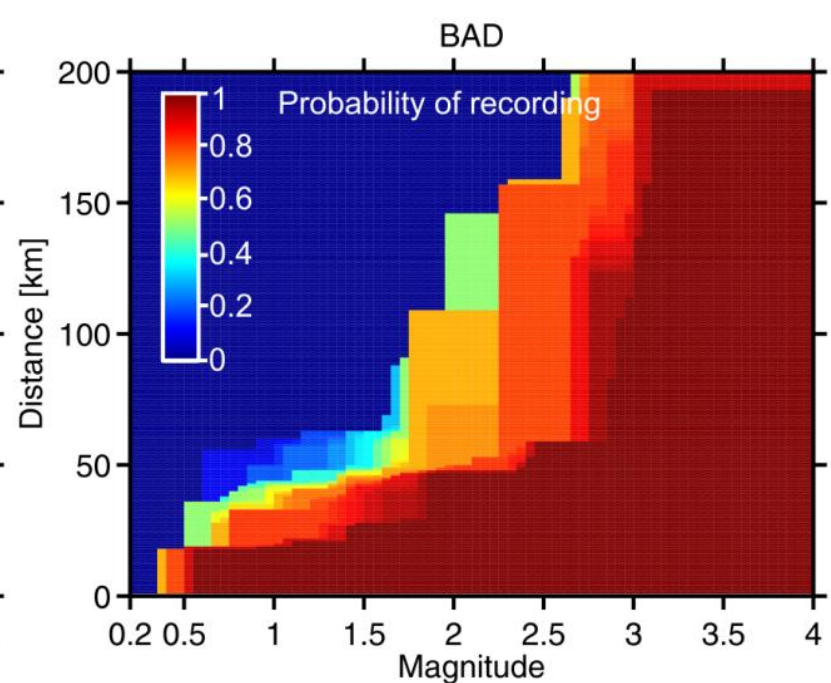

1994-1999

(f)

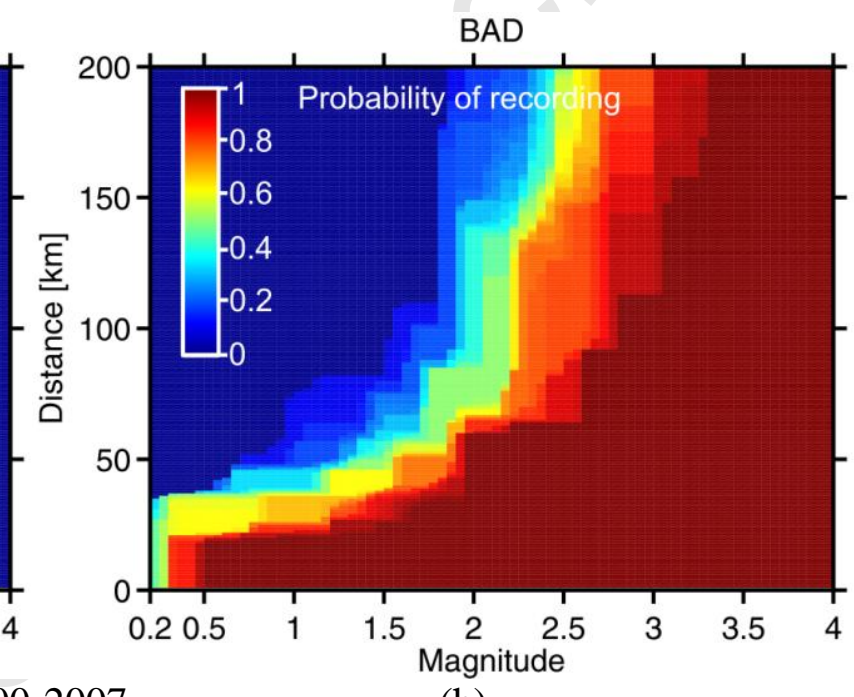

(h)

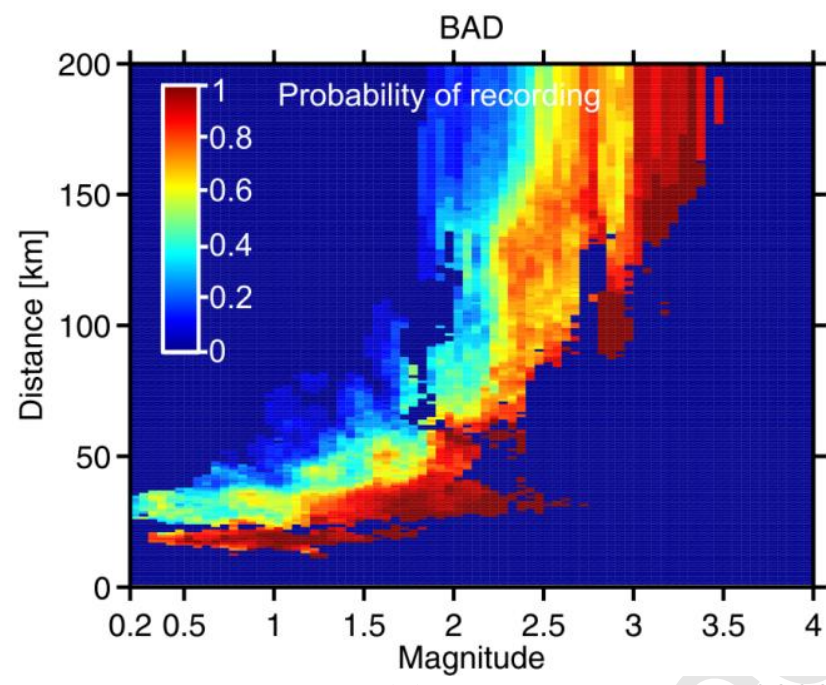

(g)
2000-2007

Fig. 8

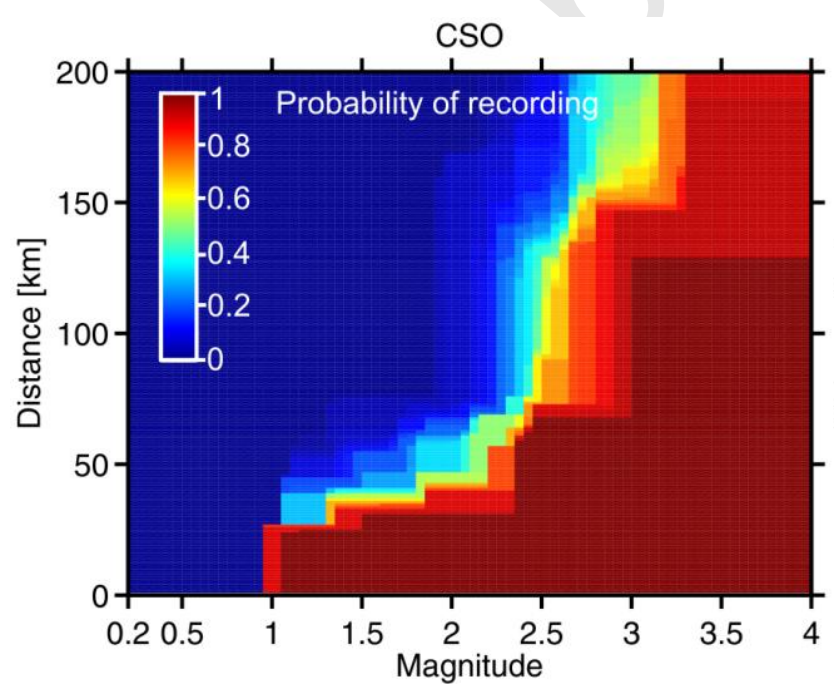

(a)

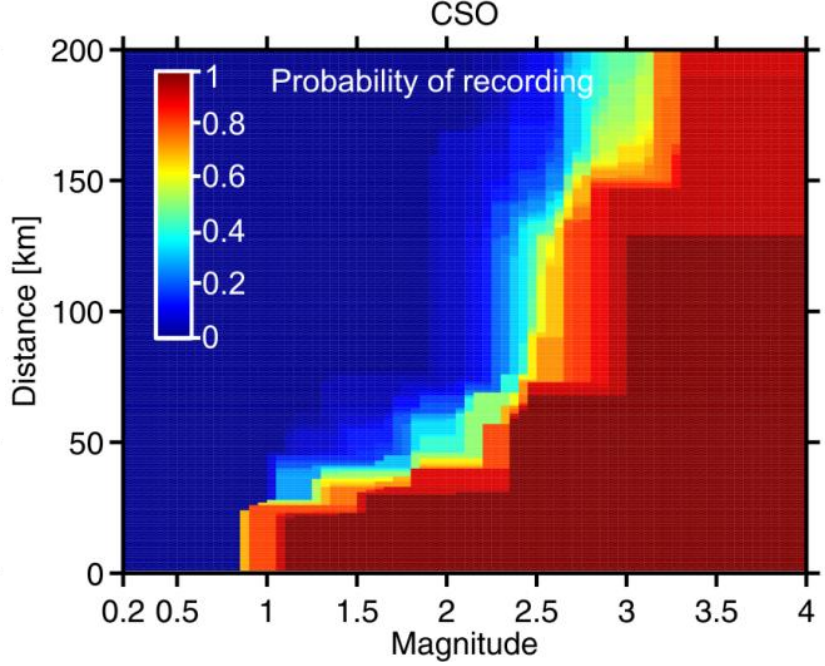

(b) 


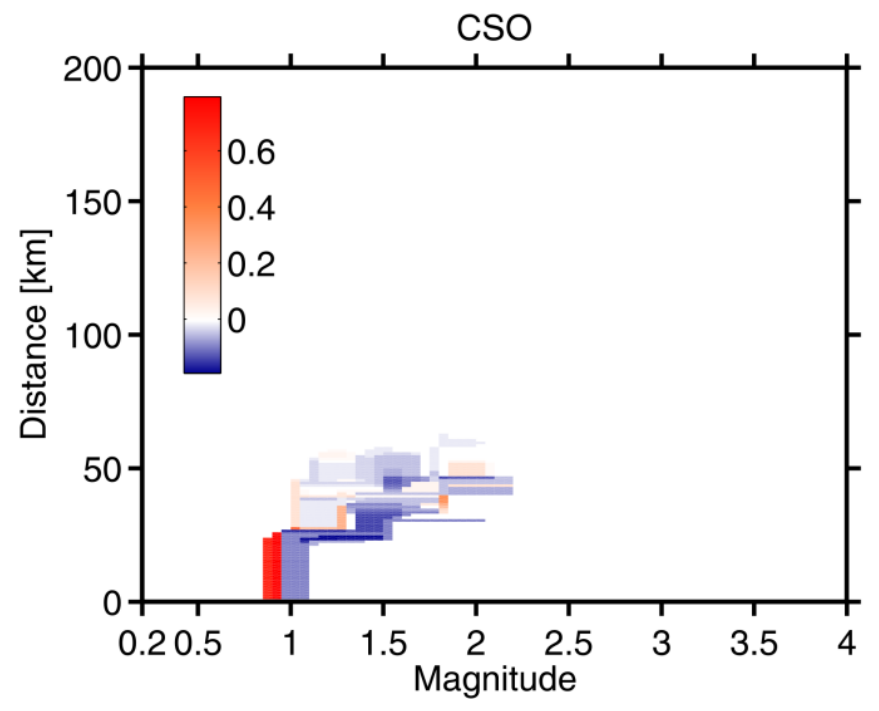

Fig. 9 

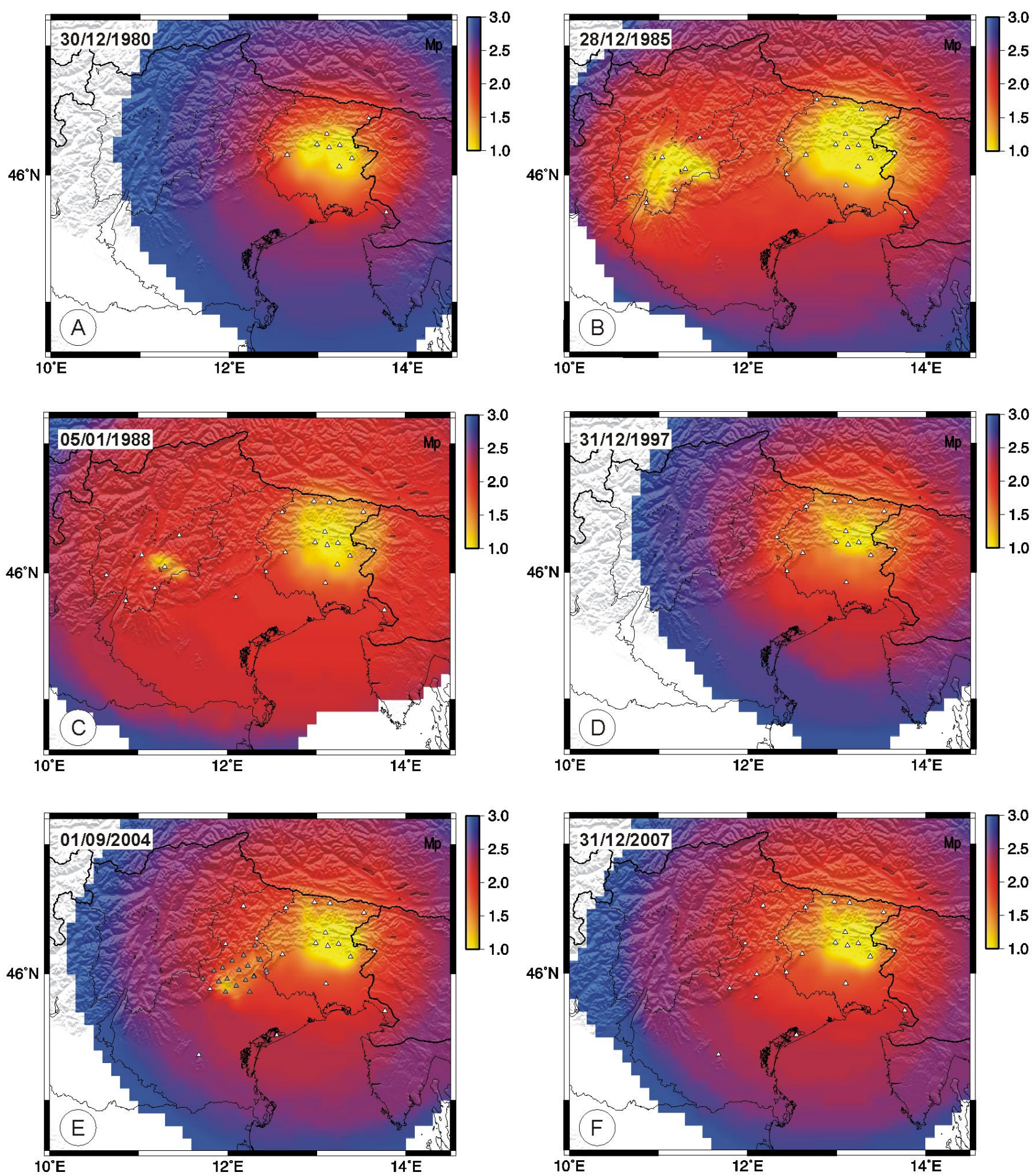

Fig 10 


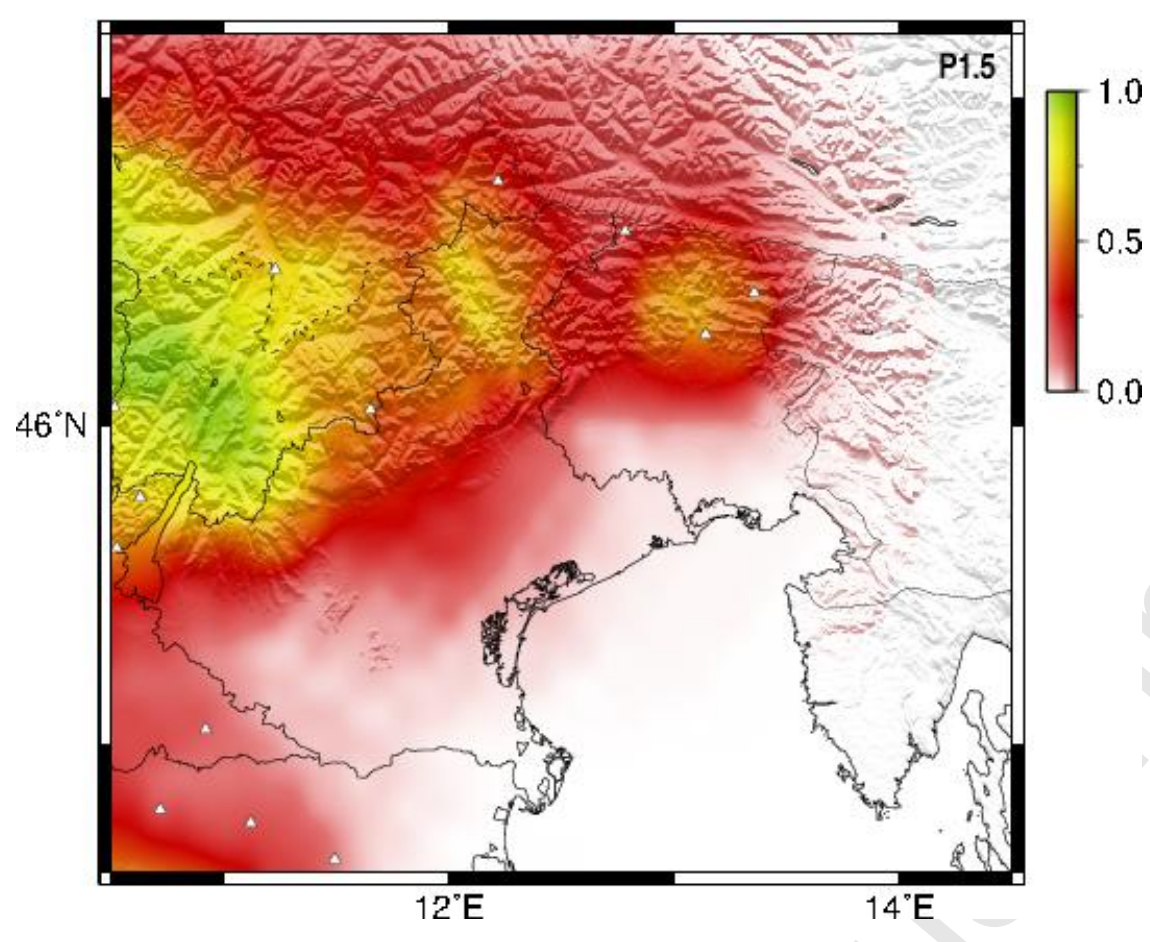

(a)

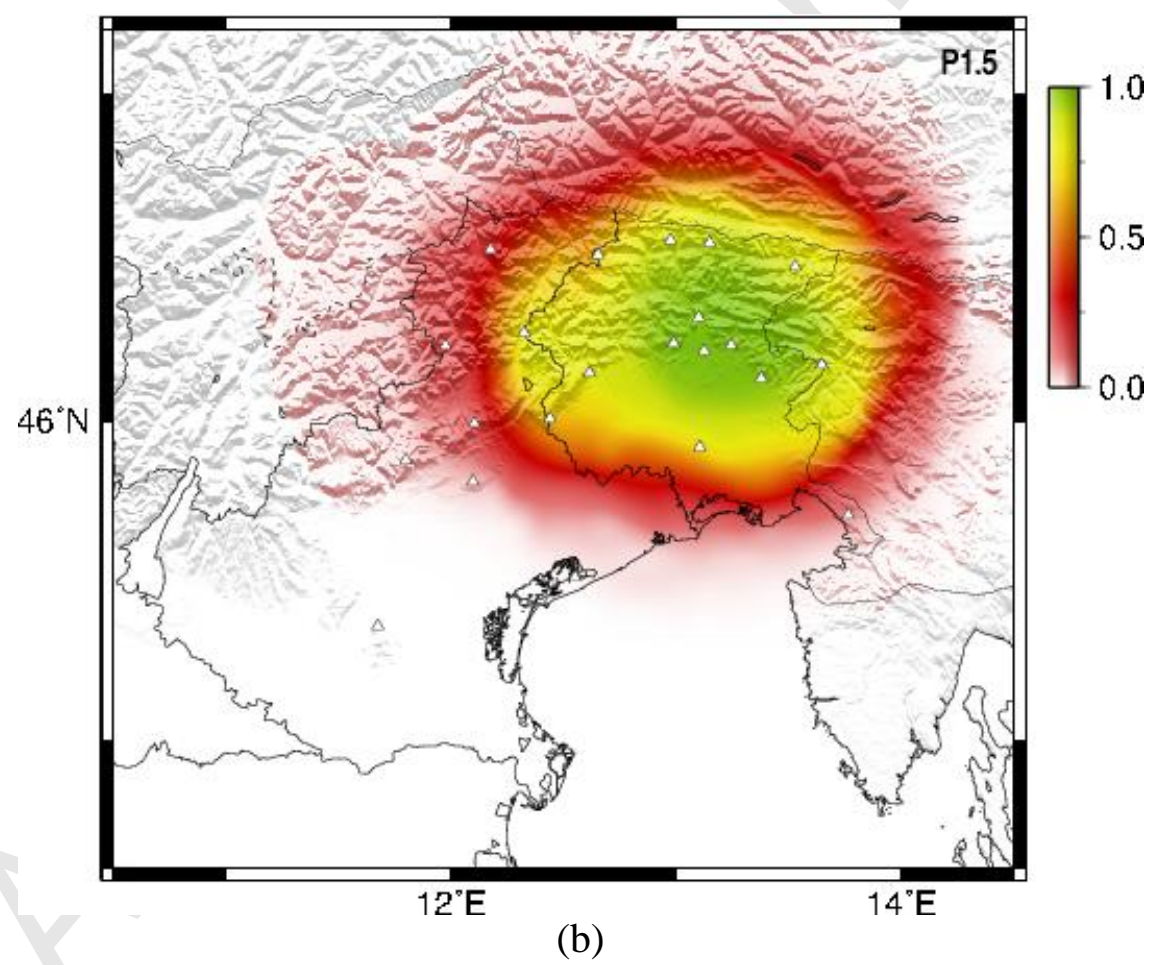

Fig 11 